Utah State University

DigitalCommons@USU

$5-1978$

\title{
Eight to Twelve Hertz Occipital EEG Training With Moderate and Severely Retarded Epileptic Individuals
}

Eric H. Rudrud

Utah State University

Follow this and additional works at: https://digitalcommons.usu.edu/etd

Part of the Psychology Commons

\section{Recommended Citation}

Rudrud, Eric H., "Eight to Twelve Hertz Occipital EEG Training With Moderate and Severely Retarded Epileptic Individuals" (1978). All Graduate Theses and Dissertations. 5874.

https://digitalcommons.usu.edu/etd/5874

This Dissertation is brought to you for free and open access by the Graduate Studies at DigitalCommons@USU. It has been accepted for inclusion in All Graduate Theses and Dissertations by an authorized administrator of DigitalCommons@USU. For more information, please contact digitalcommons@usu.edu.

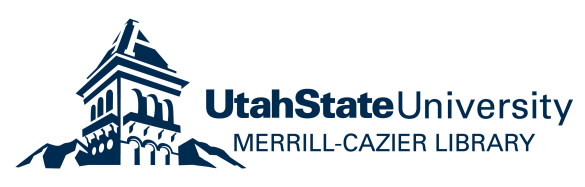


EIGHT TO TWELVE HERTZ OCCIPITAL

EEG TRAINING WITH MODERATE AND SEVERELY

RETARDED EPILEPTIC INDIVIDUALS

by

Eric H. Rudrud

A dissertation submitted in partial fulfillment of the requirement for the degree

of

DOCTOR OF PHILOSOPHY

in

Psychology

Approved:

UTAH STATE UNIVERSITY

Logan, Utah

1978 


\section{ACKNOWLEDGMENTS}

I would like to thank Dr. Sebastian Striefel, Chairman of my Doctorai Committee, for his invaluable assistance, support, encouragement, and patience throughout this endeavor. I would also like to thank Dr. Frank Ascione, Dr. Glendon Casto, Dr. Marvin Fifield, and Dr. Elwin Nielson for their support and generous patience while serving on my dissertation committee.

I would like to extend special thanks for Dr. Gary Daniels and Dr. James Maclean for allowing me to conduct this research at Parsons State Hospital and Training Center; Riley Worthy and Jerry Strait for their many hours of technical assistance; Rickey and Henry Heffner for their hours of consultation; and Carlita Milks for her friendship, assistance, and untiring support; and Neil and Donna for their many hours of consultation and constructive criticisms. 
INTRODUCTION

REVIEW OF LITERATURE . . . . . . . . . . . . . . . . . . . . . . . 4

Definition . . . . . . . . . . . . . . . . . . 4

Treatment of Epilepsy . . . . . . . . . . . . . . . . . . 8

Behavioral Approaches to Epilepsy . . . . . . . . . . . 10

Competing Responses .. . . . . . . . . . . . . . . . 10

Increasing Stimulus Tolerance . . . . . . . . . . . . . 12

Desensitization/Relaxation . . . . . . . . . . . . . . . 14

Interruption of Behavioral Chains/Differential

Reinforcement (DRO)................ . 16

Biofeedback Approaches to Epilepsy . . . . . . . . . . . . . 17

STATEMENT OF THE PROBLEM . . . . . . . . . . . . . . . . . 27

METHOD ........................... . . 29

Subjects . . . . . . . . . . . . . . . . 29

Apparatus ...................... . . . 31

Reinforcer Selection and Feedback Stimuli . . . . . . . . 32

Experimental Setting....... . . . . . . . . 34

Design . . . . . . . . . . . . . . . . . . . . 34

Data Recorded . . . . . . . . . . . . . . . 35

General Procedure . . . . . . . . . . . . 36

Baseline .. . . . . . . . . . . . . . . 37

Training . . . . . . . . . . . . . . . . . 37

Posttraining . . . . . . . . . . . . . . . . 40

RESULTS . . . . . . . . . . . . . . . . . . 4 41

Eight of Twelve Hertz Occipital EEG Activity . . . . . . . . . 41

Seizure Data... . . . . . . . . . . . . . 45

Reliability . . . . . . . . . . . . . . . 49

EEG Data... . . . . . . . . . . . . . . . . 49

Seizure Data... . . . . . . . . . . . . . 50 
Related Data.............. . . 50

EEG . . . . . . . . . . . . . . . . . 50

AM PM effects .............. . . . 52

DISCUSSION . . . . . . . . . . . . . . . . . 53

LITERATURE CITED . . . . . . . . . . . . . . . . . . . 59

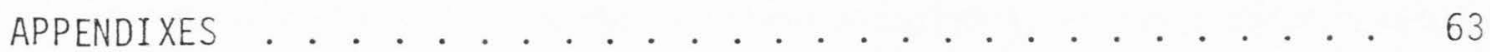

Appendix A. Difficulty in Subject Identification . . . . 64

Appendix B. Parsons State Hospital and Training Center Seizure Reporting Forms . . . . . . . 66

Appendix C. Figure 5 ............. . . 68

Appendix D. Figure 6 . . . . . . . . . . . 70

Appendix E. Figure 7 . . . . . . . . . . . 72

Appendix F. Table 4............... . . 74

Appendix G. Table 5.............. . . 75

Appendix H. Glossary of Terms . . . . . . . . . . 76

VITA ....................... 79 


\section{LIST OF TABLES}

Table

1. Training Sequence for Each Subject. . . . . . . . . . . 3?

2. Mean EEG Data for Each Subject Per Experimental Condition

3. Percent of Seizure Free Days, Actual Number of Seizure Free Days, Mean Number of Seizures Per Day, and Actual Number of Seizures Per Day for Each Subject During Baseline (B), EEG Feedback Training ( $T$ ), and PostTraining Conditions ( $P$ )

4. am/pm Effect on Daily Means of 8-12 Hz Activity, 4-8 Hz Activity, Mean Amplitude of 8-12 Hz Activity, and Mean Frequency of 8-12 Hz Activity for experimental subjects 1,2, and 3............. . 74

5. Percent of seizure free days, actual number of seizure free days, mean number of seizures per day, and actual number of seizures per day for each post hoc contro] subject during baseline $(B)$, EEG feedback training $(T)$, and Posttraining condition $(\mathrm{P})$. . . . . . . . . . 76 


\section{LIST OF FIGURES}

Figure

1. Major division of the human cortex . . . . . . . . . . 6

2. The international $10-20$ system . . . . . . . . . . . . 20

3. Mean percent of time per session within 8-12 Hz. The dotted line represents the mean percent of time for each feedback condition. The circled data points indicate a.m. sessions. . . . . . . . . . . . . . . . . . 42

4. Seizure frequency of experimental subjects during baseline training, and posttraining conditions.

Each letter indicates the type of feedback provided during specific sessions as follows:

(A) feedback was provided by $M$ \& M dispenser

(B) feedback was provided by hand delivery

(C) feedback was provided by the tape recorder

(D) feedback was provided by light panel

(E) feedback was provided by light panel and television

(F) feedback was provided by tape recorder and tickle

(G) feedback was provided by light panel and television

(H) feedback was provided by television and tickle

5. Mean percent of time per session within 4-8 $\mathrm{Hz}$ for experimental subjects 1,2 , and 3 . The dotted line represents the mean percent of time for each feedback condition. The circled data points indicate a.m. sessions.....................

6. Mean frequency of $8-12 \mathrm{~Hz}$ activity per session for experimental subjects 1,2 , and 3 . The dotted line represents the mean frequency for each feedback condition. The circled data points indicate a.m. sessions . . 70

7. Mean amplitude of $8-12 \mathrm{~Hz}$ activity per session for experimental subjects 1,2 , and 3 . The dotted line represents the mean frequency for each feedback condition. The circled data points indicate a.m. sessions. . 


\section{ABSTRACT}

Eight to Twelve Hertz Occipital EEG Training

With Moderate and Severely Retarded

Epileptic Individuals

by

Eric H. Rudrud

Utah State University, 1978

Major Professor: Sebastian Striefel, Ph.D.

Department: Psychology

A number of studies have demonstrated the effectiveness of $E E G$ biofeedback procedures in reducing seizure activity in patients who have not achieved remission through drug therapy. However, results indicate a lack of correlation between changes in seizure activity and the EEG parameters trained. Recent research has suggested that occipital alpha activity may be modified indirectly as a function of the EEG biofeedback training procedures. The present study sought to determine the effects of directly conditioning occipital alpha on seizure activity.

Three retarded epileptic individuals, who had not achieved complete remission from seizures through drug therapy, were provided with 8-12 Hz occipital EEG biofeedback training using a multiple baseline design. While seizures were not totally eliminated in any of the subjects, the results of the study indicated that all subjects 
exhibited decreases in some aspect of their seizure activity. S-1's mean number of seizures per day during EEG feedback training was lower than the baseline or posttraining conditions. Associated with this decrease in seizures was an increase in the percent of seizure free days during training as compared to baseline or posttraining conditions. S-2's mean number of seizures per day decreased during training as compared to baseline. This decrease, nowever, was not associated with an increase in the percent of seizure free days during training as compared with the baseline condition. S-3's percent of seizure free days increased during training and returned to baseline level during posttraining. The mean number of seizures per day for both the EEG feedback and baseline conditions were approximately equal, and lower than the posttraining condition.

Two of the subjects, $\mathrm{S}-2$ and $\mathrm{S}-3$, increased their percent of time of 8-12 Hz activity during the training condition, as compared to baseline levels. Associated with the increase in 8-12 $\mathrm{Hz}$ activity was a decrease in percent of time of $4-8 \mathrm{~Hz}$ activity; an increase in the mean frequency of 8-12 Hz activity; and with one subject a reduction in the mean amplitude of the 8-12 $\mathrm{Hz}$ activity.

One possible explanation for these results was the differing degree of effectiveness of the feedback stimuli in terms of their functionality as reinforcers. In addition, several differences between subjects (medication and diagnosis) may have also contributed to the results.

One possible explanation which may have accounted for the reduction in seizure frequency not being associated with an increase in $8-12 \mathrm{~Hz}$ activity was that a change in another physiological parameter may have occurred as a result of the training procedure which in turn effected 
a decrease in seizure rate. Or possibly the subjects achieved a generally lower level of arousal which was responsible for the decrease in seizure frequency.

The results of the study suggest changes in procedures will be necessary if $8-12 \mathrm{~Hz}$ occipital training is to be developed into an adjunctive therapy in the treatment of epilepsy.

Methodological improvements which would provide a more accurate assessment of the effectiveness of al1 EEG biofeedback techniques used in the treatment of epilepsy, include: selection of subjects with higher frequencies of seizures, subjects of normal intelligence, the simultaneous recording of several other physiological parameters, and the development of a more reliable monitoring system of seizure activity. 


\section{INTRODUCTION}

Epilepsy is a sudden disruption of central nervous system function that is recurrent and associated with an excessive neuronal discharge of the cortex that is self-limited (Aird and Woodbury, 1974). Cortical EEG changes that occur during epileptic seizures include the appearance of high amplitude low frequency delta-theta waves, 1-6 Hz (Hertz).

The most common modes of treatment include drug therapy, surgical management, and diet therapy; with drug therapy being the most common. However, drug therapy is not without its problems in terms of treatment effectiveness and reported side effects. Fifty to sixty percent of the total epileptic population can achieve remission from seizures through the appropriate administration of one drug (Arieff, 1974). An additional twenty percent of the epileptic population require the administration of two or more drugs to achieve remission. Remission for the remaining twenty percent is difficult to achieve. Reported side effects of drug therapy include somnolence, sedation, toxicity, and metabolic disorders (Boshes, 1974; Liftshitz and Maclarent, 1975).

Biofeedback training a promising new technique for establishing voluntary control over many physiological processes, without adverse side effects, has been effective in reducing seizure frequency in some persons who have not achieved remission through drug therapy. The technique most widely reported has been to condition the person to produce a central cortical brain wave pattern designated SMR (sensorimotor rhythm) activity by Sterman, MacDonald, and Stone 
(1974). Sterman, MacDonald, and Stone (1974) found that the production of a subdominant $12-14 \mathrm{~Hz}$ brain wave over the left sensorimotor cortex (SMR, sensorimotor rhythm) was related to processes involved in the inhibition of epileptigenic activity and a subsequent reduction in seizure incidence. Other changes that occurred as a result of SMR training included a "normalization" of the EEG in which there was an increase in the dominant frequency of the EEG from the "abnorma?" 3-6 Hz frequencies to the higher alpha 8-12 Hz frequencies. Lubar and Bahler (1976) and Finley, Smith, and Etherton (1975) reported similar findings as a result of SMR biofeedback training.

Other experimenters such as Kuhlman (1976) and Kaplan (1976) have not demonstrated an increase in SMR activity or other central rolandic frequencies $(9-14 \mathrm{~Hz}$, or $6-12 \mathrm{~Hz}$ ) as a result of biofeedback training procedures. However, they reported a shift from lower to higher dominant frequencies as measured by occipital alpha activity as a result of the training procedures. Correlated with this increase in occipital alpha activity was a decrease in seizure frequency. Kuhlman concluded that the increase in the amount of alpha activity and the shift in dominant frequency from lower to higher bands indicated that the feedback training facilitated normal resting EEG synchrony.

In summary, the effect of training the various central rhythm activities on seizure frequency appears questionable due to the lack of consistent change in these trained EEG parameters. However specific changes in the patient's EEG which occurred as a result of the training procedures are common to all procedures. These changes include: 1) an increase in the amount of occipital alpha; and 2) an 
increase in dominant frequency from lower to higher bands. In addition, these changes were correlated with a reduction in seizure frequency (Kuhlman, 1976).

The purposes of this study were two-fold: 1) to determine whether an increase in the amount of occipital alpha $(8-12 \mathrm{~Hz})$ could be conditioned in persons with epilepsy who continued to experience seizures despite medication; and 2) to determine what effects such training would have on seizure frequency. 
REVIEW OF RELATED LITERATURE

The review of literature which follows has been limited to provide the reader with information directly relevant to epilepsy and the use of biofeedback procedures in the treatment of epilepsy. The scope of this review should provide a brief synopsis of epilepsy, its origins, and methods of treatment.

Definition

Epilepsy affects approximately fifteen million people in the world today (Ward, Jasper, and Pope, 1969) and probably four million people in the United States alone (Arangio, 1974). It is among the most common neurological disorders (Schmidt and Wilder, 1968) and is defined as a sudden disturbance of central nervous system function that is recurrent and associated with an excessive neuronal discharge that is self limited (Aird and Woodbury, 1974). The seizures that occur may be associated with a wide variety of neurological disturbances i.e., disease, intoxication, electrolyte imbalance, tumor, etc., and may be transient in nature (Schmidt and wilder, 1968).

The clinical and behavioral manifestations of seizures are "as numerous as the function of the brain" (Aird and Woodbury, 1974). Some of the major factors influencing the behavioral and clinical manifestations of the seizure include the origin of the discharge, the rapidity of spread of the discharge, and synchronization.

The discharge may originate in any portion of the cortex (Aird and Woodbury, 1974; Lennox, 1960). Creutxfelt (1973) maintains that 
the cerebral cortex is the most important structure for epileptic activity because of its lower seizure threshold. Gloor (1969) presented evidence, however, that the discharge may arise from subcortical areas. Creutxfelt (1973) suggested that subcortical involvement may be a consequence of the cortical acitivity rather than a primary manifestation. The clinical aspects (EEG patterns) and behavioral manifestations of the seizures are related to the particular cortical areas involved, for example, Jacksonian epilepsy (partial seizure with motor symptoms) originates in the pre or post rolandic cortex (see Figure 1). The EEG is characterized by a rhythmic discharge of spikes and slow waves localized over the contralateral hemisphere. The behavioral manifestations consist of clonic movements in one joint, such as the thumb, that gradually spreads over the limb, beginning in the thumb and spreading to the wrist, elbow, and shoulder. Adversive seizures originate in the precentral area, anterior to the precentral gyrus (see Figure 1). The clinical manifestations include turning the eyes, or eyes and head, away from the side of the focus. Partial seizures with visual symptoms indicate an epileptic focus in the occipital areas (see Figure 1). Sensations reported during the seizure include dimming of vision, spots, lights, and dancing objects which may be either colored or uncolored.

The spread of the epileptic discharge has a major influence on the behavioral manifestations. The three major categories of seizures are partial, unilateral, and generalized seizures. In partial seizures the spread of the discharge is limited to a specific site of origin in the cortex. For example, in Jacksonian epilepsy, a partial 


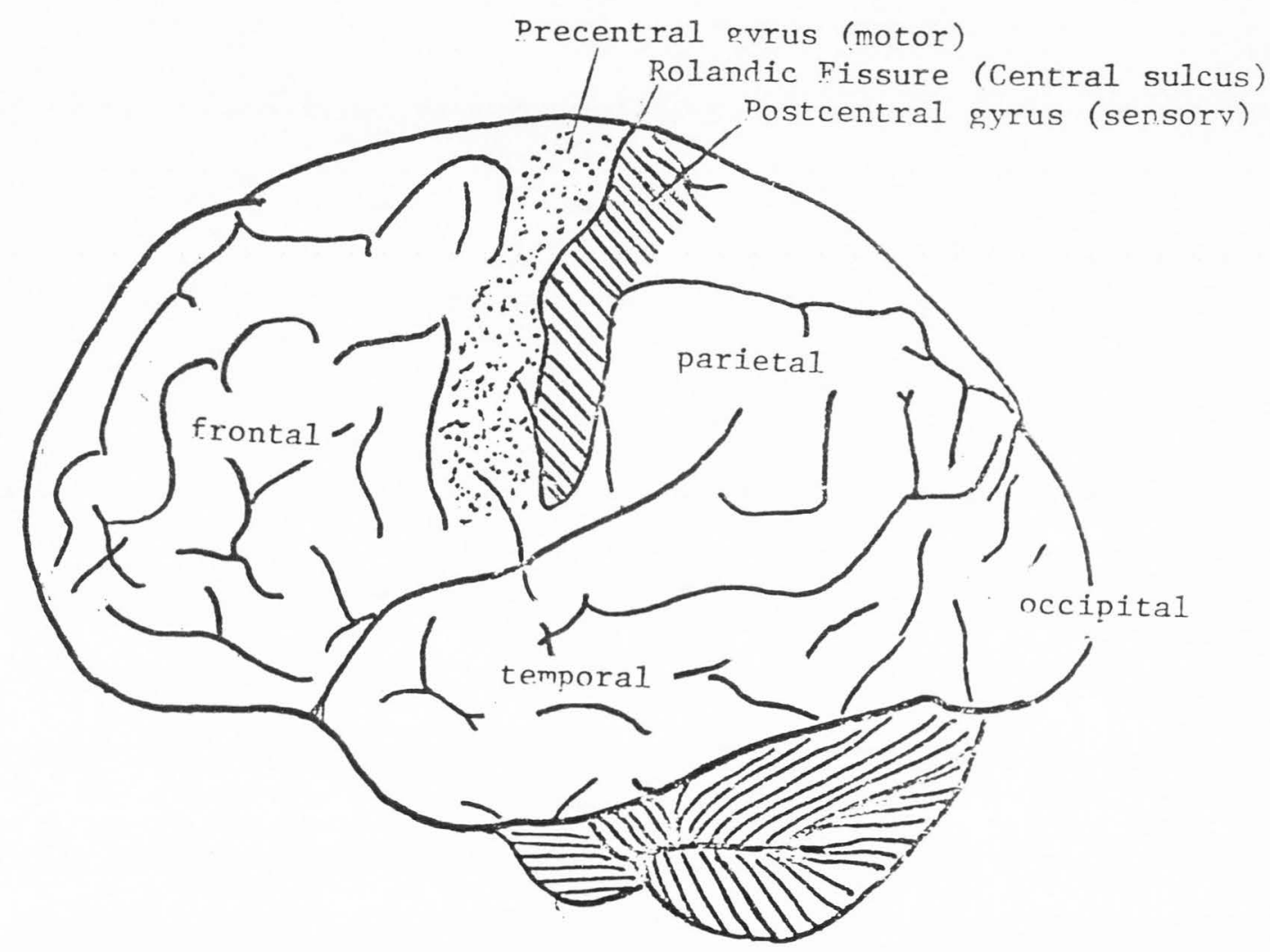

Figure 1. Major divisions of the human cortex 
seizure, the discharge is limited to the precentral area of the cortex (see figure 1). In unilateral seizures the discharge spreads rapidly from the site of origin over the entire hemisphere. For example, with unilateral tonic-clonic seizures, the tonic-clonic contractions are restricted to only one side of the body (Schmidt and Wilder, 1968). Generalized seizures are characterized by complete cortical involvement from the onset of the seizure and the behavioral manifestations are diffuse such as in petit-mal and grand-mal seizures.

The spread of the discharge over the cortex seems to be directed towards the rolandic gyri (Penfield, 1941). If the discharge reaches the motor region after traveling over the cortex, there is usually an explosive discharge of the region that spreads to the opposite hemisphere and basal ganglia (Penfield, 1941). If the discharge starts locally in the precentral gyrus, a Jacksonian march may occur, indicating that the spread is occurring in an immediately adjacent portion of the gyrus. The elementary or complex symptomatology of the seizure depends on whether the discharge of a system is localized in one or both cortical hemispheres. A major difference between partial seizures and unilaterial seizures is that in the partial seizure the discharge remains in a local area, whereas in the unilateral seizure the discharge spreads rapidly over the entire hemisphere.

The synchronization of the brain waves determines the type of seizure. Partial seizures are characterized as having a rhythmic discharge of spikes and slow waves while generalized seizures are characterized by bilateral synchronous and symmetrical discharges. Poirel (1971) concluded that the synchronization among differing 
cortical areas during low vigilance permits resonance between subcortical and cortical systems that can trigger epileptic seizures. Treatment of Epilepsy

"An ideal antiepileptic drug should be capable of complete suppression of seizures, regardless of the type, at a dose level which produces no other signs or symptoms of drug effect... Unfortunately such a drug is not currently available" (Schmidt and Wilder, 1968, p. 142). The control of seizures in most persons with epilepsy is based upon the regular administration of anticonvulsant drugs. However, drug therapy is not without its problems in terms of treatment effectiveness and reported side effects. Fifty to sixty percent of the total epileptic population can achieve remission from seizures through the appropriate administration of one drug. An additional twenty percent of the epileptic population require the administration of two or more drugs to achieve remission. Remission for the approximate remaining twenty percent has not been achieved through drug therapy (Arieff, 1974).

Another drawback associated with drug therapy is side effects. Phenobarbital is the most widely used anticonvulsant (Schmidt and Wilder, 1968) and is used mainly for the control of generalized convulsive seizures and focal seizures. However, phenobarbital is limited in its effectiveness due to its sedative effects, Other reported side effects of phenobarbital include scarlatiniform dermatitis, edema of the face and eyelids, hepatic failure, drowsiness, and dizziness (Schmidt and Wilder, 1968). 
Diphenylhydantoin (Dilantin) is another widely used anticonvulsant. Reported side effects that may occur due to its chronic use or overmedication include lethargy, drowsiness, confusion, Perkinje cell degeneration in the cerebellum, inhibition of or competition for vitamins essential to the central nervous system function, gum hypertrophy which may require resection of the hypertrophied gum tissue, hepatitis, hirsutism, and in some cases of a single massive dose, an irreversible coma and death. Common side effects reported by other anticonvulsant drugs include somnolence, sedation, toxicity, and metabolic disorders (Boshes, 1974; Liftshitz and Maclaren, 1973).

Surgical management of epilepsy is another approach which may be considered for those patients in which drug therapy has failed.

Schmidt and Wilder (1968) state three primary criteria for candidate selection. They are:

1. Continuing serious disability from seizures in spite of adequate anticonvulsant medication.

2. Consistent localization of an EEG focus in a brain area which can be removed without producing catastrophic disability.

3. The availability of a surgical team specifically experienced in the specialized techniques of epileptic surgery.

The results of surgical management, however, are not encouraging. Surgical management results in complete remission in approximately fifty percent of the patients. Approximately twenty-five percent of the patients "benefit" from surgery with the remaining twenty-five percent of patients exhibiting no improvement or a worsening of seizures (Schmidt and Wilder, 1968). 
Apparantly remission for approximately twenty percent of the epileptic population has proven to be a difficult task when utilizing drug therapy and/or surgical management. As a result various nonpharmacologic approaches to the treatment of epilepsy have been investigated. In particular, research in the areas of biofeedback and behavioral intervention have reportedly been successful.

\section{Behavioral Approaches to Epilepsy}

A variety of behavioral techniques (competing responses, relaxation/desensitization, DRO, and interruption of behavioral chains) have been utilized with success, in the treatment of epilepsy. This suggests that environmental events effect seizure behavior in certain individuals and manipulation of such events should not be overlooked as a potential mode of treatment for those patients who have not achieved complete remission through drug therapy.

\section{Competing Responses}

In 1881 Sir William Gower (as cited in Efron, 1956), reported using competing responses (Adams, 1976) in the treatment of seizures. Gower reported that at times seizures could be stopped by muscular exertion, such as walking quickly around the room, or by presenting a strong olfactory stimulus such as ammonia to the nostrils. Efron (1956) reported a case in which the patient had continued to experience $7-18$ seizures per month for 26 years despite medication. The patient reported a very distinct aura which lasted anywhere from 10 minutes to several hours. Efron (1956) instructed the patient to make competing responses of inhaling strong odourous substances (hydrogen sulphide) prior to reaching the "half way" point of her 
aura. The subject experienced success in aborting her seizures, however, due to the toxic side effects of inhaling hydrogen sulphide other noxious stimuli were tried. Success was achieved with stimuli that were definitely strong and unpleasant i.e., pure jasmine, and chemicals such as dimercaprol, n-ethylbutyrate, skatole and hapteness which have odors similar to hydrogen sulphide. In addition to arresting seizures Efron (1956) recorded the patients EEG and attempted to induce seizures with metrazol injections. The results indicated that when the patient inhaled a noxious stimulus in an effort to arrest a seizure the abnormal discharges on the EEG dissapated, with the EEG returning to normal activity within a few seconds of inhaling the stimulus.

Efron (1957) extended his research with the same subject by conditioning the arrest of seizures to a visual stimulus and finally to a "thought" about a bracelet. The patient received conditioning trials every 15 minutes for a period of eight days. During the trials the patient was presented with the concentrated odor of jasmine (which had been found effective in arresting her seizures; Efron, 1956) and instructed to stare intently for 15 to 30 seconds at a silver bracelet. During the second week the patient was exposed to the two stimuli only twice daily. A spontaneous seizure occured during this week and it was arrested by the patient staring at the bracelet. The clinical EEG data collected, supported these findings. The patient further reported that she could inhibit seizures by just thinking intently about the bracelet and at the time of publication the patient had remained seizure free for a period of fourteen months. 
Forster, Paulsen, and Baughman (1969) reported using a competing response technique with a case of reading epilepsy. The patient reported experiencing nervous feelings, twitches of the facial muscles, muttering of "Ah..." which then culminated into a convulsive seizure while reading aloud. Correlative EEG data was obtained when the client was requested to read the Gettysburg Address. The patient was instructed to tap his thigh each time he saw the articles "the" and "a". However, there were long stretches in the text whithout these articles and some seizures and discharges occurred. The subject was then instructed to tap his thigh each time the letter "a" or "e" occurred. When this was done no seizure or abnormal EEG patterns occured during reading. The patient was able to read for longer periods without seizures and the competing response was gradually changed to tapping with his fingers rather than hand and then simply pressing his fingers together. After several trials the patient was eventually able to read the Gettysburg Address without attending to vowels and without abnormal EEG discharges.

\section{Increasing Stimulus Tolerance}

Adams (1976) stated that reflex epilepsies are a subgroup of epilepsies in which the seizure is precipitated by some particular stimulus, stimulus class, or stimulus complex. The behavioral techniques used in the treatment of these reflex epilepsies have involved increasing stimulus tolerance, introducing the stimulus at innocuous levels and increasing the stimulus intensity and/or duration, all without the appearance of seizures. 
Forster (1967) reported success with this procedure with seizures induced by flashing lights. The patient was placed in a room where the level of ambient light was greater than the flashing stimulus. The level of ambient light was reduced, in logarithmic steps, so that the epileptic stimulus became more noticable. The patient was monitored by an EEG and if no abnormal discharges or behavioral signs occurred, the ambient light was lowered to the next level. This training continued until the epileptic stimulus could be perceived in the absence of ambient illumination and absense of epileptiform activity.

Similarly Forster, Hansotia, Cleeland, and Ludwig (1969) reported treating a case of voice-induced epilepsy by increasing the duration of exposure to the epileptic stimulus. The subject began to experience seizures two years after being involved in an automobile accident in which she had sustained a severe head injury. The patient experienced generalized tonic-clonic seizures and temporal lobe partial seizures. The generalized seizures were brought under control with medication, however, the partial seizures continued. The partial seizures occurred almost exclusively while listening to a radio with the voices of three particular announcers being highly evoking; R.Z., E.D., and R.H.

The conditioning procedure consisted of multiple presentations of each radio announcers taped voice and two presentations of all three radio announcers voices. In addition the patient was given a tape of the voices so that she could listen to it in her own room. After repeated presentations of R.Z.'s first tape no seizures or abnormal EEG discharges occurred. After 27 presentations of R.Z.'s first tape, tape 2 was presented and tape 2 did not produce any clinical or 
EEG changes. The voices of E.D. and R.H. were similarly presented until they did not evoke seizures or abnormal EEG presentations. The patient was exposed to 64 presentations over 27 trials and remained seizure free for a two month period. At this time the local radio station employed a new announcer whose voice apparantly had similar noxious qualities. After returning for additional trials over a period of two days the patient had been seizure free for a six month period.

\section{Desensitization/Relaxation}

Related to the above procedures of increasing stimulus tolerance or rendering noxious stimuli innocuous, several studies have reported utilizing desensitization/relaxation procedures to eliminate seizures.

Parrino (1971) reported using desensitization procedures with seizures that occurred in the presence of specific anxiety-provoking stimuli. The patient was a resident of a psychiatric ward who participated in a work adjustment program. From behavioral observations and self report, it appeared that the patient's seizures were triggered by particular anxiety provoking situations centered around socialization contexts i.e., socialization with other, initiating a conversation, etc. The patient was taught deep muscle relaxation and after being relaxed he was systematically presented with a ten step hierarchy. Seizures ceased to occur after continuation of treatment on an outpatient bases. In addition, there was a reduction in the severity of the seizures from gross motor movements at the beginning to tick like mannerisms at the termination of inpatient treatment. 
Ince (1976) used a relaxation/desensitization procedure with a twelve year old male who experienced absence and generalized tonic clonic seizures. Systematic desensitization treatment was for anxiety associated with recurrent seizures. Relaxation was accomplished through a "pseudo-hypnotic" suggestive tape recording, and the patient was required to practice relaxation at home twice daily. Hierarchies for desensitization were comprised in the following areas: seizures in school, seizures on baseball field, being ridiculed by other children, and receiving new experimental medication. After five sessions the patient stated that he was no longer "nervous."

Following this, the patient was relaxed twice during each session and once relaxation had occurred, he was instructed to say "Relax" slowly to himself 10 times. the child was further instructed to say "Relax" to himself repeatedly whenever he experienced an aura. This procedure resulted in the elimination of both the absence and generalized tonic-clonic seizures. Follow up during a nine month period indicated that the child remained seizure free.

Cabral and Scott (1976) investigated two desensitization techniques, biofeedback and relaxation, in three subjects who continued to experience seizures despite medication. Two subjects were exposed to biofeedback training and then relaxation training while the third subject was first exposed to relaxation training followed by biofeedback training. The biofeedback training was for 8-12 $\mathrm{Hz}$ occipital EEG activity of $10 \mathrm{mV}$ or greater. One electrodes was located $2 \mathrm{~cm}$ above the inion and the other at the vertex, see figure 2 . The relaxation training was ala Jacobson, (1938). The anxiety/phobic responses of patient 1 were because she was overweight, patient $2^{\prime}$ 's were related to 
her impending marriage, and patient 3 had a variety of social phobias. Each patient was monitored by ECG and EEG. Patients were presented with specific anxiety-provoking stimuli (APS) or imagery and the production of alpha and heart rate were monitored. The results of the study indicated that during biofeedback training the amount (in seconds) of alpha activity during the resting state increased from 22 to 64 seconds per two minute epoch. In addition the presentation of the APS produced a marked decrease in the amount of alpha activity in all subjects, however, this decrement was less evident at the end of the treatment period. Relaxation produced an average 15 percent decrement in heart rate while the presentation of the APS caused an increase of about 10 percent during the first treatment session. During the last treatment session no significant change in heart rate occurred with the presentation of the APS.

Seizure data indicated that both relaxation and biofeedback decreased each patients seizure frequency. During a 15 month follow-up the patients seizure rate remained below baseline levels.

\section{Interruption of Behavioral Chains/}

Differential Reinforcement (DRO)

Zlutnick, Mayville, and Moffat (1975) investigated the feasibility of decreasing seizure rates by identifying and interrupting reliable preseizure behaviors. For subjects 1 through 4 the interruption procedure for preseizure behavior was a loudly shouted "No!" followed by grasping the subject by the shoulders with both hands and giving one vigorous shake. For subject 5 a differential reinforcement (DRO) procedure was used contingent upon the reliable preseizure behavior of arm raising. The DRO procedure consisted of placing the subject's hands 
down to her side or lap and after a five second wait, delivery of reinforcement for "arms down." The results indicated that three of the four subjects involved with the interruption procedure and the DRO subject experienced a reduction in seizures and maintained these reductions during various follow-up periods.

Balaschak (1976) reported reducing the seizure frequency of an 11 year old epileptic girl by utilizing a behavioral program implemented by her classroom teacher. A program was designed in which the teacher divided the school day into three periods and recorded whether or not seizures occurred during these periods. The subject was reinforced with candy and verbal praise contingent upon a seizure-free week at school. During the baseline period of 50 school days the subject experienced 30 seizures. Following the implementation of the program the subjects seizure rate dropped to four seizures during a 24 school day period.

\section{Biofeedback Approaches to Epilepsy}

Kamiya (1962) demonstrated that humans could be trained to control their EEG activity with biofeedback training. Since then many other investigators have replicated these findings (Kamiya, 1969; Beatty, 1972 and Black, 1972). An obvious benefit from this biofeedback training would be to prevent epileptic seizures by having the patient suppress an epileptiform pattern of brain waives, or generate an EEG pattern that is incompatible with the epileptiform pattern. Research with biofeedback in epilepsy has reportedly been successful in generating a brain wave rhythm that is incompatible with seizure activity. Sterman and Wyrwicka (1967) termed this pattern the Sensorimotor Rhythm or SMR. SMR was described as a 12-16 Hz EEG rhythm recorded from the 
sensorimotor cortex and was first observed in cats. This rhythm was associated with relaxation (Roth, 1967), a somewhat rigid and motionless posture, and the suppression of motor activity (Sterman and Wyrwicka, 1967).

Wyrwicka and Sterman (1968) demonstrated that with the use of operant conditioning techniques a cat could learn to control the occurrence of SMR activity when reinforced with either food or positive brain stimulation. In a later experiment (Sterman, LoPrest, and Fairchild, 1969), investigating menomethylhydrazine toxicity in cats, Sterman used the same cats that had participated in SMR training. It was found that there was a significant delay of convulsions in those cats with prior SMR conditioning. Nontrained cats succumed to lethal seizures.

Further neurological investigations have localized the SMR rhythm in the somatosensory cortex and suggest its origins are within the ventrobasal nuclei of the thalamus (Harper and Sterman, 1972). These findings led Sterman to propose that the learned production of SMR could lead to a raised threshold for central nervous system seizure discharge. Sterman and Friar (1972) determined that a localized rhythm resembling the SMR could be recorded from the rolandic area and this rhythm could be brought under operant control through biofeedback techniques. They then examined the effects of SMR training in an epileptic human subject.

The subject was a 23 year old white female with a history of convulsions dating back to age 16. Her disorder consisted of nocturnal generalized major motor seizures. Neurological examinations failed to demonstrate a localized lesion. An EEG showed generalized spike-wave 
activity increased by hyperventilation and some evidence of focal activity in the left fronto-parietal area. The convulsion was preceded by a nonspecific aura, and there were no localizing features to any precipitating factors in the prodronal or postictal period.

EEG activity was monitored from the rolandic and occipital cortex. EEG patterns were recorded from the scalp using longitudinal bipolar needle electrodes, with the anterior lead intermediate between $\mathrm{F}_{3}$ and $C_{3}$ sites and the posterior lead between $C_{3}$ and $P_{3}$ (International 10-20 System, see Figure 2). The EEG signals entered amplifiers from a polygraph into a seven channel filter and logic system. The logic system was capable of frequency analysis, automatic detection of specific frequencies, and selection of precise signal to noise, duration and interval criteria for activation of feedback devices. The SMR is a subdominant frequency of $12-14 \mathrm{~Hz}$ varying from 5 to $20 \mathrm{uv}$ (microvolts). Filters were used to isolate the SMR from the raw EEG. Sterman shaped SMR at the higher voltages by adjusting the amplitude logic system. The feedback device consisted of two rows of 10 lamps and two chimes. When SMR signals met the criterion amplitude and duration, the lamps were lit, accompanied by one of the two chimes. With different combinations of lights and chimes it was possible to obtain 200-300 rewards per sessions.

The patient was isolated in a comfortable, dimly lit room and was instructed to keep her eyes open, clear her mind, and think of past experiences or of nothing at all in an effort to achieve the desired mental state. She received training for periods lasting 30 minutes to one hour which were held twice a week. 


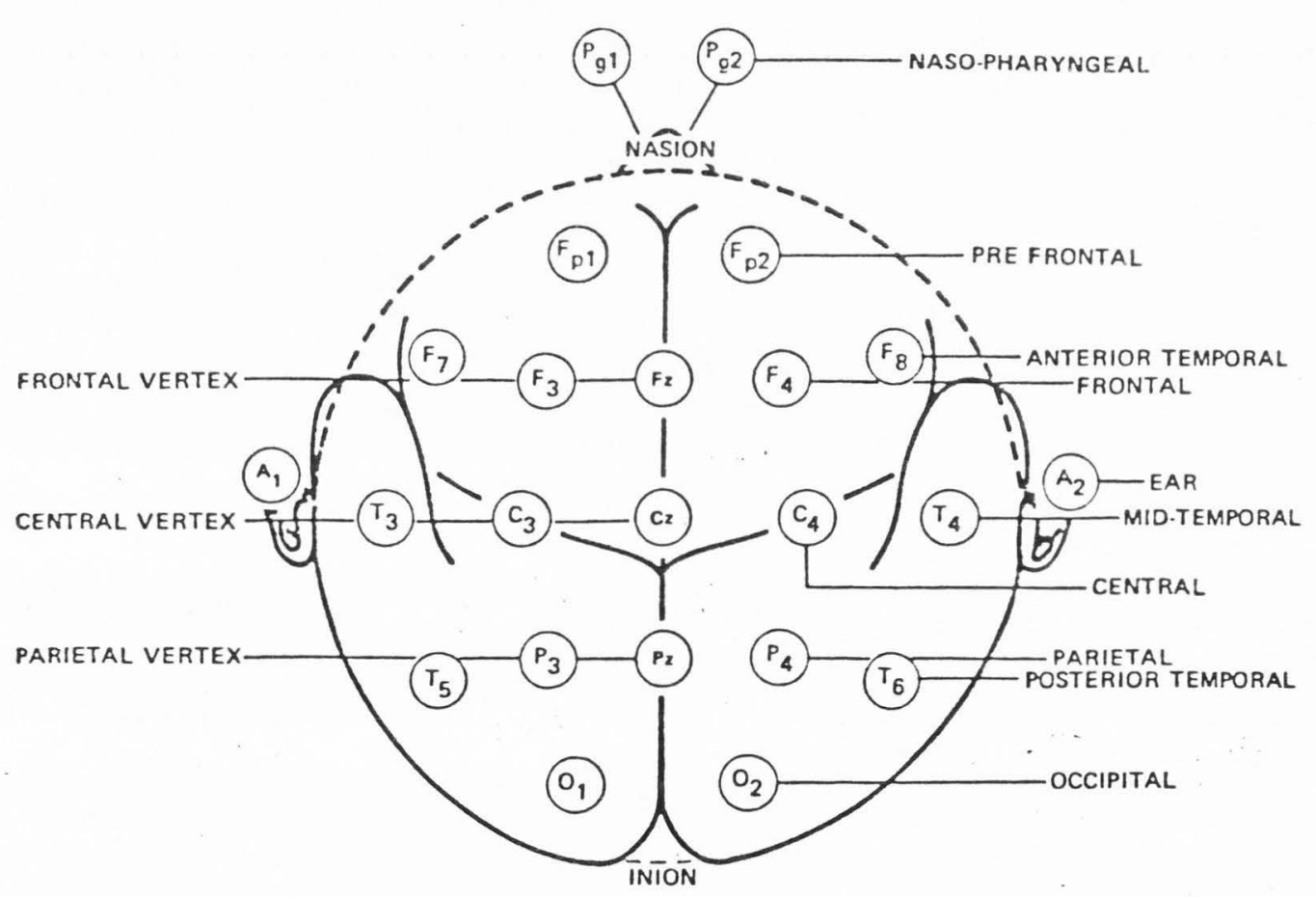

Figure 2. The international 10-20 System 
During the first few sessions there was no evidence of SMR learning. However, by the 12 th session there was selective enhancement of SMR. Six days after the first training session the patient experienced two seizures. After the third session, in which SMR learning was demonstrated, there was no further seizures for three months. There were seven seizures in the next 18 months and just one in the next six months. Though not documented objectively, Sterman and Friar (1972) reported that the patient showed sleep patterns characteristic of cats trained in SMR production and "beneficial" changes in her personality. The patient also discontinued her practice of supplementing anticonvulsant medication upon experiencing an aura, without seizure, and reported a reduction in these occurrences (Sterman and Friar, 1972).

Sterman, Macdonald, and Stone (1974) reported further data on four epileptics, ages 6, 18, 23, and 46 years and four nonepileptics. The epileptics were referred to the program because chemotherapy had failed to satisfactorily control their seizures. The subjects were diagnosed as having mixed and focal seizures which were considered "uncontrollable" by a series of neurologists. They received a minimum of three biofeedback training sessions per week for periods ranging from 6 to 18 months.

Bilateral recordings were made by independent bipolar electrodes placed over the left and right central cortical areas from a point 10 percent off vertex to a point 30 percent off vertex with references to the total interaural distance. Recordings from vertex to left and right occipital cortex were also made. The epileptic subjects were trained using EEG signals from the left hemisphere. 
Biofeedback training provided visual and auditory feedback for the appropriate EEG signal, which was defined as a function of frequencies, voltage, and duration of rhythms appearing over the left somatosensory cortex. The signal was detected by a Neuro Feedback Instruments Neuro Analyzer set to respond to a $13 \mathrm{~Hz}$ activity at a minimum voltage ( 5 uv) and lasting for .75 seconds. The response was attentuated sharply in either direction resulting in reinforcement of rhythmic activity in the $12-14 \mathrm{~Hz}$ band. Relay outputs from other filters turned off the feedback logic channel during the presence of an undesirable pattern (movement artifacts, polyspike, and slow-wave discharges). The same feedback device described in Sterman and Friar (1972) was used. The same general instructions were also given to the epileptics for biofeedback training.

It was found with the nonepileptics that 12-16 Hz activity could be detected in the EEG with training and that there were three partially independent frequencies apparent over the central and frontal cortex. A 9-11 Hz rhythm during pretraining was associated with a similar dominant frequency from the parietal cortex (alpha). During biofeedback the dominance shifted to peaks at 12-14 $\mathrm{Hz}$ or 14-16 $\mathrm{Hz}$ or both, primarily over the central and frontal cortex, while parietal 9-11 Hz activity showed marked attenuation. Also, after several months of training, a degree of cortical EEG asymmetry was noted. With the epileptics, pretraining recordings showed a central cortical frequency ranging from 5 to $9 \mathrm{~Hz}$. These subjects seldom showed the clear 12-16 Hz patterns seen in the nonepileptics. However, they did demonstrate a marked and localized increase in the filter 
detected SMR occurrences. There was also a distinct unilateral prevalence on the left hemisphere, the side which was trained.

The results of SMR training in epileptics showed a gradual reduction in high voltage slow-waves, spikes or both. The EEG patterns obtained during state two sleep showed significant improvements with training. Major motor seizure frequency was reduced in all epileptic patients during training. These results were not observed before two or three months of regular and continuous training. There was a significant reduction of EEG and clinical epileptic manifestations.

Finley (1974) reported the effects of SMR training of a 13 year old white male diagnosed as "petit mal type" with three spike-wave discharges per second. Prior to training, he was averaging 75 falling type seizures for every 10 hours of wakefulness. He was maintained on Valium, $30 \mathrm{mg}$ t.i.d., and Phenobarbital $60 \mathrm{mg}$ t.i.d. through SMR training.

The biofeedback electrode was located between $\mathrm{C}_{3}$ and $\mathrm{F}_{3}$ and was referenced to $\mathrm{A}_{2}$ (International 10-20 system). Note: no ground electrode was used as a result only two electrodes were utilized. The EEG signal was amplified and passed through two adjustable band pass filters tuned to $12 \pm 1 \mathrm{~Hz}$ and $5.5 \mathrm{~Hz} \pm 1.5 \mathrm{~Hz}$. The $12 \mathrm{~Hz}$ relay and feedback apparatus were activated by $12 \mathrm{~Hz}$ activity equal to or greater than 5 uv. The patient showed $12 \mathrm{~Hz}$ activity about 10 percent of the time prior to training. The $5.5 \mathrm{~Hz}$ filter was used to monitor the occurrence of epileptiform discharges. When these occurred, they interrupted the $12 \mathrm{~Hz}$ feedback.

The subject was rewarded for $12 \mathrm{~Hz}$ production by receiving one point for every five seconds of SMR activity he accumulated. A "beat 
the clock" game was introduced in which the subject tried to accumulate a certain number of points before the time on a clock in the front of him elapsed. He was then rewarded with one to three dollars. He received one hour of feedback training three times a week.

Beginning with session 35 , the subject was provided with feedback of his epileptiform activity. When epileptiform activity occurred, a red light was turned on and the subject was instructed to attempt to turn the red light off since he could not accumulate points when it was on.

The results showed the subject's percentage of SMR increased from approximately 10 percent prior to training, to 65 percent by the 34 th training session. His rate of clinical seizures decreased by a factor of ten along with a significant reduction in the percentage of epileptiform discharges. There was a significant negative correlation between SMR production and epileptiform discharges.

During a one year follow-up, Finley (1975) noted seizure and epileptiform discharge rate were maintained at a low level and the percentage of SMR had been maintained at a higher level than baseline. In addition, noncontingent feedback was introduced for approximately two months, during the follow-up period. This resulted in a significant decrease in SMR production and a significant increase in epileptiform discharges. Seizure rate also increased but this was not significant. Kaplan (1975) was unable to replicate the findings of Sterman et a1. (1974) and Finely (1974). Kaplan provided 12-14 Hz biofeedback training to two epileptics, however, there was no apparent effect on the subject's clinical EEGs, seizure incidence or proportion of EEG 
spectral power as a result of the training procedures. In a subsequent experiment she provided $6-12 \mathrm{~Hz}$ rolandic biofeedback training, however, again no apparent learning of $6-12 \mathrm{~Hz}$ activity was detected and she concluded that the changes in seizure incidence were not attributed to EEG feedback. However, Kaplan (1975) indicated that there was an increase in occipital alpha rhythm activity in two subjects who showed decreases in seizure frequency. She concluded that this may have been a nonspecific effect of the laboratory setting or a general relaxation effect.

As a result of the above findings, Kaplan (1975) cautioned that the results reported by Sterman, et a1. (1974) must be viewed as tenative due to the reported evidence for change in 12-14 Hz activity. She indicated that the 12-14 Hz EEG data reported by Sterman, et al. (1974) had not been subjected to statistical analysis (such as an increase in the percentage of time that the activity is present) and that it is difficult to make inferences as to the cause of seizure reduction without a correlated change in EEG activity. While Finley (1974) reported an increase in the percentage of time in SMR activity, Kaplan (1975) pointed out that there is a discrepancy in the definition of SMR activity. Sterman, et a1. (1974) reported that SMR activity was not blocked by contralateral movement while Finley (1974) reported that SMR did block to contralateral fist clenching.

Kuhlman (1976) also failed to replicate the results of Sterman, et a1. (1974). Kuhlman provided feedback for the production of 9-14 $\mathrm{Hz}$ rolandic activity. However, the most reliable change in the subject's EEG during training was an increase in the amount of occipital alpha. Accompanying this increase of occipital alpha in one subject 
was an increase in the occipital alpha frequency which was a mirror image of seizure frequency. Also reported was a shift in dominant frequency from lower to higher bands which has been reported to occur following surgical treatment for epilepsy. Kuhlman (1976) concluded that the increase in the amount of alpha activity and the shift in dominant frequency from lower to higher bands indicated that the feedback training facilitated normal resting EEG synchrony and that this apparent "normalization" is associated with seizure reduction. 
STATEMENT OF THE PROBLEM

Several researchers (Sterman and Friar, 1972; Sterman, MacDonald, and Stone, 1974); Finley, (1974) have reported using SMR biofeedback training $(12-14 \mathrm{~Hz})$ to decrease seizure activity in subjects who had not achieved complete remission of seizures through drug therapy. However, Kaplan (1975) was not able to replicate Sterman, MacDonald, and Stone's (1974) results and cautioned that conclusions regarding the conditioning of $12-14 \mathrm{~Hz}$ activity must be viewed as tenative especially in light of the evidence that the 12-14 Hz EEG data reported by Sterman, et al. (1974) had not been subjected to statistical analysis. Kaplan (1975) also noted that it is difficult to make inferences as to the cause of seizure reduction without a correlated change in EEG activity. While Finley (1974) reported an increase in the percentage of time in SMR activity, Kaplan (1975) pointed out that there is a discrepancy in the definition of SMR activity. Sterman, et al. (1974) reported that SMR activity was not blocked by contralateral movement while Finley (1974) reported that SMR did block to contralateral fist clenching. Kuhlman (1976) was also not able to replicate the results of Sterman, et al. (1974). Kuhlman (1976 successfully reduced seizures by training 9-14 Hz central rolandic activity. However, no increase in either $9-14 \mathrm{~Hz}$ central rolandic or $12-14 \mathrm{~Hz}$ (SMR) activity was observed. In contrast $8-12 \mathrm{~Hz}$ occipital alpha, which was also recorded, increased apparently as an indirect consequence of the training. 
The effect of training $12-14 \mathrm{~Hz}$ SMR and $9-14 \mathrm{~Hz}$ central rolandic activity on seizure frequency appears questionable due to the lack of correlation between changes in seizure activity and the EEG parameters. However, specific changes occur in the EEG that are associated with a reduction in seizures as a result of SMR or 9-14 $\mathrm{Hz}$ biofeedback training. These changes include: 1) an increase in the amount of occipital alpha and, 2) an increase in dominant EEG frequency from lower to higher bands. These observations raised the question of whether seizure activity could be reduced by directly training subjects to increase their occipital alpha. The purposes of the present study were:

1. Determine whether a direct increase in the amount of occipital alpha (as measured by percent of time within 8-12 Hz) could be conditioned in retarded adults with epilepsy who had not achieved complete remission from seizures through medication.

2. Determine what effect such training would have on seizure frequency. 
METHOD

\section{Subjects}

The study was conducted at Parsons State Hospital and Training Center (PSHTC) in Parsons, Kansas after a preliminary search for subjects in Utah provided futile (See Appendix A). Three subjects from a total population of 42 mentally retarded epileptic patients at PSHTC were identified who met the following criteria: 1) the subjects had been diagnosed by a neurologist as having epilepsy; 2) the subjects had a minimum of ten seizures per month for two months prior to involvement in the study, as determined by a review of hospital records;

3) no changes in medication had occurred within four weeks prior to involvement in the study; and 4) parental permission for involvement in the study had been obtained by hospital staff using hospital established procedures.

Subject 1 was a 17 year 4 month old male who was functioning at the moderate level of mental retardation with both measured intelligence (Heber, 1959) and adaptive behavior (Grossman, 1973) at Level III. The diagnostic impression by the staff of PSHTC was mental retardation, moderate, associated with cerebral defect, congenital, further associated with major motor seizures, speech defect, psychiatric impairment characterized by depression and apathy, and motor dysfunction (mild right hemiparesis). He appeared to be solemn, withdrawn, and to have lost interest in life because of seizure activity and heavy medication. He wore protective headgear because of his seizures. He 
communicated by pointing to various objects and his few verbalizations were echolalic in nature.

His seizure activity was first noted at 13 months of age and he currently received the following medication:

$$
\begin{aligned}
& 400 \mathrm{mg} \text { Tegretol od } 9: 00 \text { p.m. } \\
& 200 \mathrm{mg} \text { Tegretol tid } 6: 30 \mathrm{a} . \mathrm{m} ., 12: 00 \text { p.m., 4:00 p.m. } \\
& 125 \mathrm{mg} \text { Diamox eod } 6: 30 \mathrm{a} . \mathrm{m} . \\
& 10 \mathrm{mg} \text { Librium od } 9: 00 \mathrm{p.m} .
\end{aligned}
$$

Subject 2 was a 22 year 5 month old female who was functioning at the moderate level of mental retardation with both measured intelligence and adaptive behavior at level III. The diagnostic impression by the staff of PSHTC was mental retardation moderate, associated with cerebral defect, congenital, primary cranial anomaly (microcephaly), with speech disarticulation and mixed seizure disorder, psychomotor.

Her seizure activity was noted at age 15, shortly after her admission to PSHTC. She currently received the following medication:

$$
\begin{aligned}
& 250 \text { mg Mysoline qid } 8: 00 \text { a.m., 12:00 p.m., 4:00 p.m., } \\
& \text { 8:00 p.m. } \\
& 100 \text { mg Dilantin bid } 12: 00 \text { p.m., 8:00 p.m. }
\end{aligned}
$$

Subject 3 was a 19 year 5 month old male who was functioning at the severe level of mental retardation with both measured intelligence and adaptive behavior at level IV. The diagnostic impression by the staff of PSHTC was mental retardation, severe, associated with cerebral defect of unknown origin, possibly of congenital nature, but more probably associated with postnatal encephalitis at 17 months of age, further associated with mixed seizure disorder, speech defect, and motor dysfunction. He walked with an awkward gait, fell easily, and had particular difficulty walking up and down stairs. He wore a protective helmet because of his seizures. 
His seizure activity was first noted at the age of 2 years 9 months and he currently received the following medication:

$$
\begin{aligned}
& 400 \mathrm{mg} \text { Tegretol tid 8:00 a.m., 3:30 p.m., 8:00 p.m. } \\
& 100 \mathrm{mg} \text { Dilantin bid 8:00 a.m., 8:00 p.m. } \\
& 250 \mathrm{mg} \text { Mysoline bid 8:00 a.m., 8:00 p.m. } \\
& 500 \mathrm{mg} \text { Mysoline od 3:30 p.m. }
\end{aligned}
$$

During the course of the experiment no changes in the subjects' medication occurred.

\section{Apparatus}

The biofeedback equipment consisted of an Autogenics Systems, Inc. Feedback Encephalograph, Model 120 a, and a Narco Systems Physiograph Model DMB 48. The feedback encephalograph monitored the subjects' EEG and was equipped with adjustable frequency and amplitude filters. These filters were adjusted to define the EEG parameters that resulted in feedback e.g., 8-12 Hz with 0-15 mv. The feedback encephalograph had a meter which indicated the percentage of time the subjects' EEG was within the amplitude and frequency selected, for a period of 10, 20, $50,250,1000$, and 2000 seconds. The feedback encephalograph also displayed by meters, the average frequency and amplitude of the subjects' EEG within the defined parameters for the past accumulated 10, $20,50,250,1000$, and 2000 seconds of such activity.

In addition, the feedback encephalograph had two auxillary outputs, raw EEG and logic, which were interfaced with the Narco Systems Physiograph. This allowed each subjects' EEG to be recorded on paper.

Directly below the EEG tracing was another pen which deflected whenever the subjects' EEG was within the defined parameters that resulted in feedback. 
Reinforcer Selection and Feedback Stimuli

A list of various edible and non-edible stimuli that had been used as reinforcers for each subject was obtained from PSHTC staff who had direct training experience with the subjects. The experimenter initially delivered $M$ \& $M$ candies (which had been identified as reinforcers) by using an $M$ \& $M$ dispenser. However, due to electrical interference with the encephalograph the use of the dispenser was discontinued. Subsequentiy, a variety of reinforcers were displayed in an ice cube tray (e.g. M \& M's, candy mints, pretzels, cookies) and the subjects selected their choice of one reinforcer from those displayed.

One of the following was used to provide feedback to the subjects during the training condition (see Tabie 1).

1. $A M$ \& $M$ dispenser delivered a $M$ \& $M$ candy into a tray whenever the subject produced an $8-12 \mathrm{~Hz}$ response of .5 seconds duration.

2. A 10 display light panel with one lamp lighting in sequential order for each $8-12 \mathrm{~Hz}$ response of .5 seconds duration.

3. A tape recorder provided an instrumental music selection whenever the subject produced an $8-12 \mathrm{~Hz}$ response. The music remained on as long as the 8-12 $\mathrm{Hz}$ activity was present.

4. A 19 inch black and white television provided videotaped "Popeye" cartoons with sound whenever the subject produced an 8-12 Hz response. The cartoon remained on as 1ong as the 8-12 $\mathrm{Hz}$ activity was present.

All subjects received a minimum of seven sessions when feedback was provided by tape recorded music. If the mean percent of time within 
Table 1

Training Sequence for Each Subject

\begin{tabular}{|c|c|c|c|c|c|}
\hline Subject & Sessions & Days $^{a}$ & Condition & Feedback & Mechanism \\
\hline \multirow[t]{7}{*}{1} & $1-10$ & $37-45$ & Baseline & & \\
\hline & $11-24$ & $46-53$ & Training & $\begin{array}{l}\text { Feedback } \\
\text { Encephalograph }\end{array}$ & M\&M Dispenser \\
\hline & $25-27$ & $54-56$ & Training & Feedback & $\begin{array}{l}\text { M\&M Hand } \\
\text { Dispensed }\end{array}$ \\
\hline & $28-34$ & $57-60$ & Training & Tape Recorder & Choice of edibles \\
\hline & $35-37$ & $67-64$ & Training & & $\begin{array}{l}\text { Light panel } \\
\text { Choice of edibles }\end{array}$ \\
\hline & $38-44$ & $65-69$ & Training & Tape Recorder & $\begin{array}{l}\text { Light panel } \\
\text { Choice of edibles }\end{array}$ \\
\hline & $45-74$ & $70-90$ & Training & Television & $\begin{array}{l}\text { Light panel } \\
\text { Choice of edibles }\end{array}$ \\
\hline \multirow[t]{2}{*}{2} & $1-20$ & $37-50$ & Baseline & & \\
\hline & $21-65$ & $51-72$ & Training & Tape Recorder & Pennies \\
\hline \multirow[t]{4}{*}{3} & $1-30$ & $37-58$ & Baseline & & \\
\hline & $31-37$ & $59-64$ & Training & Tape Recorder & Choice of edibles \\
\hline & $38-55$ & $65-77$ & Training & Tape recorder & $\begin{array}{l}\text { Choice of edibles } \\
\text { Tickle }\end{array}$ \\
\hline & $56-75$ & $78-90$ & Training & Television & $\begin{array}{l}\text { Choice of edibles } \\
\text { Tickle }\end{array}$ \\
\hline
\end{tabular}

a. Days corresponding to Figure 3. 
8-12 $\mathrm{Hz}$ during these seven sessions was below the mean percent of time within 8-12 Hz during baseline sessions, alternate feedback stimuli were sought. In general, alternate feedback stimuli were introduced if the subject's continued production of 8-12 Hz activity was below baseline level or exhibited a sharp decreasing trend (minimum of three data points); and when constructed and tested so that electrical interference did not occur.

\section{Experimental Setting}

The individual sessions were conducted in a dimly lit, 2.59 meters by 2.74 meters soundproof, electrically isolated, chamber (Industrial Acoustics Co., Bronx, New York).

Design

A multiple baseline design with replication across subjects was used (Baer, Wolf, and Risely, 1968). The multiple baseline design requires continuous recording of the dependent variables of several subjects during baseline and experimental conditions. The independent variable is then introduced to each subject at different points in time, during baseline. If changes in the dependent variables are due to the presentation of the independent variables, this will occur sequentially upon the presentation of the independent variable to each subject. The dependent variables that were continuously recorded were seizure frequency, and amplitude of 8-12 Hz occipital EEG activity, and percent of time within $8-12 \mathrm{~Hz}$ and $4-8 \mathrm{~Hz}$ with no amplitude criterion.

The multiple baseline design is particularly useful when reversing the treatment conditions is undesirable (Baer, Wolf, and Risley, 1968). Other advantages of this design are (a) all subjects are exposed to the 
treatment conditions, (b) a small subject sample can be used, (c) the possible effects of extraneous experimental variables such as time per se, placebo effects such as baseline manipulations, attention, etc. are controlled and (d) it applies to individuals which is what clinicians deal with in the field.

\section{Data Recorded}

Occipital EEG data was recorded from electode positions $0_{7}$ and $T_{3}$, which are located over the left occipital cortex and temporal lobe (see Figure 2). A ground electrode was placed over position $T_{4}$ which is $10-$ cated over the right temporal 10be. The frequency filters on the feedback encephalograph were set at 8-12 $\mathrm{Hz}$ and 4-8 $\mathrm{Hz}$. The amplitude

filter was adjusted so that $8-12 \mathrm{~Hz}$ activity, between $0-150 \mathrm{mv}$ in amp 1 itude, was analyzed to compute percent of time, mean frequency, and mean amplitude. At 60 second intervals the experimenter recorded percent of time, mean frequency and mean amplitude of alpha production during the processing periods by reading meters on the feedback encephalograph. The percent of time the subject's occipital EEG was within 8-12 Hz and 4-8 Hz was computed for the past 50 seconds of real time. The mean frequency and amplitude of 8-12 Hz EEG activity was computed for the past 20 seconds of accumulated $8-12 \mathrm{~Hz}$ activity. In addition, the raw EEG was recorded by the physiograph.

Seizure frequency data reported in this study were obtained form each subject's medical file. As part of PSHTC policy, in-house staff members responsible for direct care of patients were instructed in seizure observation and recording procedures, and were required to complete a seizure report form whenever a patient was observed to have 
a seizure. During experimental sessions and the time required to escort the subjects to and from the laboratory, the experimenter was responsible for observing seizures and filling out seizure report forms. Information recorded on the seizure report form included the date and time of day the seizure occurred, type of seizure (major convulsion, focal convulsion, minor convulsion, etc., see Appendix B). Seizure data were collected around the clock by the staff and the experimenter and were then transcribed into the subjects' medical file by the cottage nurse. Thus, a complete record of seizure activity for each subject in the study was available to the experimenter.

\section{General Procedure}

Experimental sessions were held twice a day, Monday through Friday, and on Saturday morning, whenever possible. Each subjectwas seen at the same time each day: $S_{1}$ at 8:15 am and 3:00 pm; $S_{2}$ at 7:45 am and 4:30 $\mathrm{pm} ; \mathrm{S}_{3}$ at 8:45 am and 3:30 pm. Experimental sessions were 18 minutes in duration. The experimenter was present in the experimental chamber during al1 session in order to monitor and control behaviors which might cause muscle artifact interference in the EEG e.g., movement in the chair, gritting teeth, etc. Whenever a subject engaged in this type of behavior, the experimenter told the subject to "rest" or "sit" which resulted in a cessation of the behavior. These behaviors, however, occurred very infrequently during the course of the study. During each session the subject sat in an "overstuffed" chair and was fitted with a headband securing surface electrodes to his scalp over position $O_{1}$ and $\mathrm{T}_{3}$ with a ground electrode over $\mathrm{T}_{4}$ (see Figure 2). 
Baseline

The previously noted seizure frequency data were collected from each subject's medical file. The fact that hospital procedures required collection of seizure frequency data gave the experimenter flexibility in choosing the length of the seizure baseline period for each subject. In order to facilitate analysis it was decided that the length of the seizure baseline period should be equal to the length of both the EEG feedback training and posttraining conditions for each subject (Hersen and Barlow, 1976). For $S_{1}, S_{2}$, and $S_{3}$ the lengths of the baseline, EEG feedback training, and posttraining conditions were, 45, 29, and 32 days respectively. In addition, during the last 9 days of baseline for $S_{7}$, 14 days of baseline for $S_{2}$, and 21 days of baseline for $S_{3}$, EEG recordings were taken once or twice daily. During these days $S_{7}$ received 10 session, $S_{2} 20$ sessions, and $S_{3} 30$ sessions of baseline EEG recordings. Prior to the introduction of treatment each subject's percent time within 8-12 Hz had to meet a stability criteria. The stability criteria was that each subject's mean percent time of 8-12 $\mathrm{Hz}$ activity for the last session had to be with in \pm 1 standard deviation of the mean of the last three EEG baseline sessions. During EEG baseline sessions each subject was fitted with electrodes and told to sit quietly in the chair and rest. Each subject received reinforcement at the end of each EEG baseline session (their choice of candies, cookies, or pennies).

\section{Training}

The training sequence for each subject is shown in Table 1. Since the basic design of the study was a multiple baseline, the subjects were introduced to treatment after various amounts of EEG baseline data were 
collected, $S_{1}$ after $10, S_{2}$ after 20 , and $S_{3}$ after 30 session. In general, during training sessions subjects were instructed to turn on the feedback apparatus (music, television, etc.) and received reinforcement for the production of $8-12 \mathrm{~Hz}$ activity of .5 seconds or longer.

During sessions 11 through 24 (see Table 1), S, received feedback for the production of $8-12 \mathrm{~Hz}$ activity in the form of a varying pitch tone. The tone varied in pitch across the range for which feedback was provided, a frequency of $8 \mathrm{~Hz}$ being associated with a low tone and 12 $\mathrm{Hz}$ being associated with a high tone. In addition, $M$ \& $M$ candies were delivered, by the $M$ \& $M$ dispenser, contingent upon the production of 8-12 Hz activity of at least .5 seconds or 1onger duration. One M \& M candy was delivered for each half second of 8-12 Hz activity. Following session 24 it was discovered that the $M$ \& $M$ dispenser was causing electrical interference with the EEG recordings and was discontinued as a means of providing reinforcement. During sessions 25 through $27 \mathrm{~S}_{7}$ continued to receive feedback from the feedback encephalograph, however, $M$ \& $M^{\prime}$ s were hand dispensed by the experimenter who determined that .5 seconds of $8-12 \mathrm{~Hz}$ activity had occurred by monitoring a light in the experimental chamber but out of the subject's line of vision. Dispensing M \& M's by hand was included to confirm the hypothesis that the $M$ \& $M$ dispenser may have caused inaccurate amplitive readings (see Appendix F). During the three sessions when $M \& M^{\prime} s$ were hand dispensed, $S_{1}$ 's mean amplitude decreased to a mean value of 55 uv as compared to a mean of 84 uv during the last seven sessions when $M \& M$ \& were delivered by the $M \& \|$ dispenser. After 17 sessions of tone feedback and contingent $M$ \& $M^{\prime} S S_{1}$ showed no significant change in 8-12 Hz EEG activity. Therefore, it was decided 
that this procedure should be discontinued and music feedback introduced in an effort to train this subject. During sessions 28 through $34, \mathrm{~S}_{1}$ received tape recorded instrumental music as feedback and selected his choice of various edibles for producing an $8-12 \mathrm{~Hz}$ response of .5 seconds duration. $S_{1}$ 's mean percent of time of 8-12 Hz EEG activity, during these seven sessions was below his baseline mean and another feedback stimulus was introduced. During sessions 35 through $37, S_{7}$ received feedback in the form of a 10 light display panel. Each lamp lit in sequence contingent upon an 8-12 $\mathrm{Hz}$ response of .5 seconds duration. $S_{7}$ also received his choice of various edibles when the lamps 1it. However, during these three sessions, $S_{7}$ 's production of 8-12 Hz activity decreased sharply below baseline values and the tape recorded music was re-introduced (sessions 38 through 54). Since $S_{7}$ 's production of $8-12 \mathrm{~Hz}$ activity was still below the mean baseline value after 17 sessions an alternate mode of feedback was introduced. During sessions 45 through $74, S_{1}$ received feedback from the 1 ight panel, presentation of videotaped cartoons, and his choice of edibles.

$\mathrm{S}_{2}$ received tape recorded music as feedback during sessions 21 through 65. In addition, $S_{2}$ received one penny for every 50 seconds of accumulated 8-12 Hz activity. Pennies were delivered by the experimenter at the end of each session.

$S_{3}$ received tape recorded music as feedback during sessions 31 through 37 , as well as his choice of various edibles. Following session 37 the experimenter learned from a PSHTC staff member that physical contact (i.e. tickles, pats, etc.) was a reinforcer for $S_{3}$. During sessions 38 through $55, \mathrm{~S}_{3}$ was tickled vigorously by the 
experimenter. In addition, $S_{3}$ received his choice of various edibles for production of $8-12 \mathrm{~Hz}$ activity. Since $\mathrm{S}_{3}$ had not shown a large increase in his production of $8-12 \mathrm{~Hz}$ activity after 25 sessions with tape recorded music as feedback, a change in feedback was introduced. During sessions 56 through $75, S_{3}$ received feedback in the form of videotaped cartoons as well as his choice of edibles and tickles.

\section{Posttraining}

Following the training period each subject's seizure frequency was monitored for a number of days equal to the number of days of training he/she had received. The seizure frequencies were obtained from each subject's medical file. 
RESULTS

\section{Eight to Twelve Hertz Occipital EEG Activity}

Each subject's percent of time within 8-12 Hz is shown in figure 3. A summary of this data and related EEG data is provided in Table 2. Table 2 and Figure 3 show that $S-7$ 's mean percent of time within 8-12 Hz decreased from a mean of 34.27 percent during the 10 EEG baseline sessions to a mean of 27 percent during the 64 EEG feedback training sessions. S-2's mean percent of time within 8-12 Hz increased from a mean of 36.82 percent during the 20 EEG baseline sessions to an overall mean of 63.25 percent during the EEG feedback training conditions. S-3's mean percent of time within $8-12 \mathrm{~Hz}$ decreased from a mean of 33.72 during 30 baseline sessions to a mean of 25.05 percent during the seven sessions when music feedback was provided by a tape recorder. However, when the experimenter provided tickles for 8-12 Hz production (in addition to the tape recorder, sessions 38-55) $\mathrm{S}-3$ increased his production of $8-12 \mathrm{~Hz}$ activity to 40.33 percent of time. S-3 maintained this approximate level of 8-12 Hz production throughout the remainder of the EEG training condition when feedback was provided by television (sessions 56-75, see Table 2).

In summary, S-2 was the only subject who demonstrated an increase in percent of time in 8-12 $\mathrm{Hz}$ activity as a result of the EEG feedback training procedure when music feedback was provided. S-1 showed a decrease in the percent time in 8-12 $\mathrm{Hz}$ activity and S-3 initially 

Figure 3. Mean percent of time per session within 8-12 Hz. The dotted line represents the mean percent of time for each feedback condition. The circled data points indicate a.m. session 
SUBJECT I

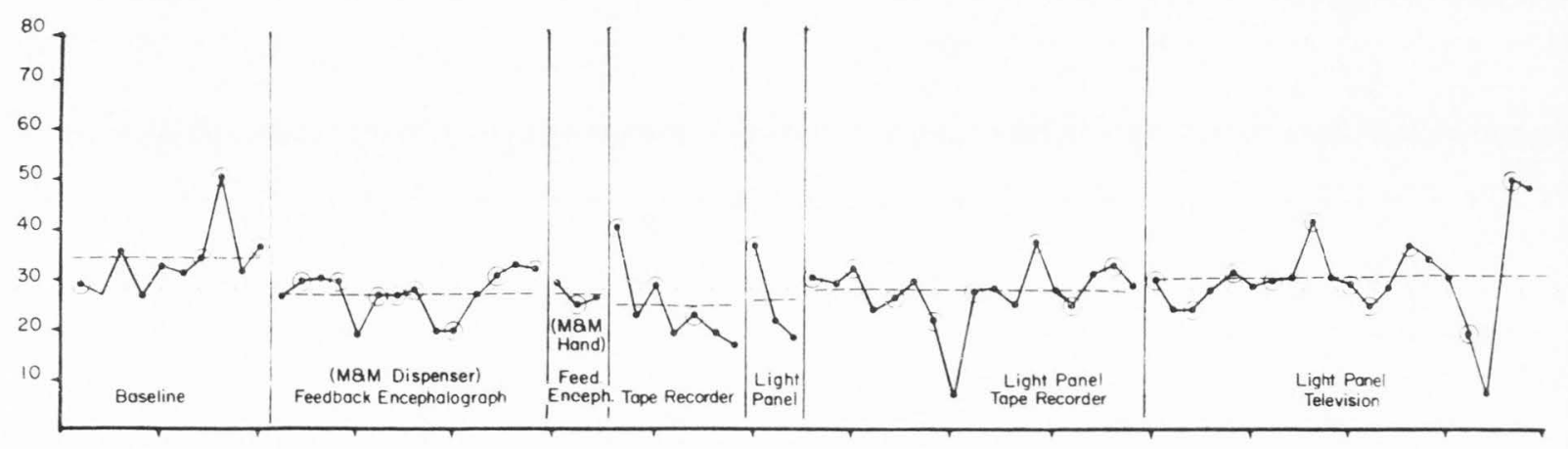

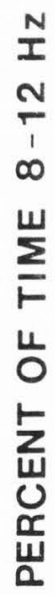

SUBJECT 2

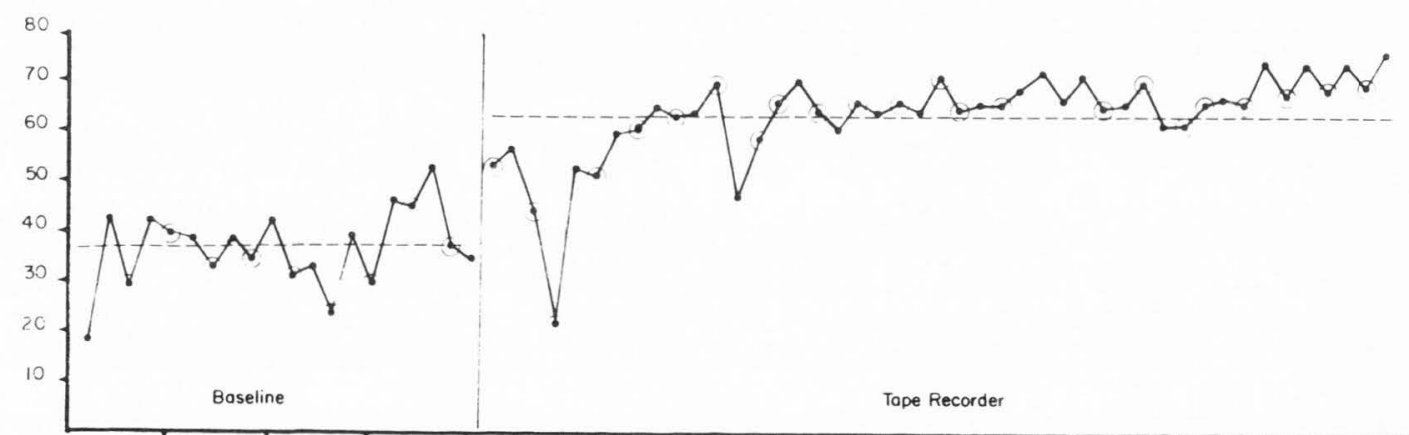

SUBJECT 3

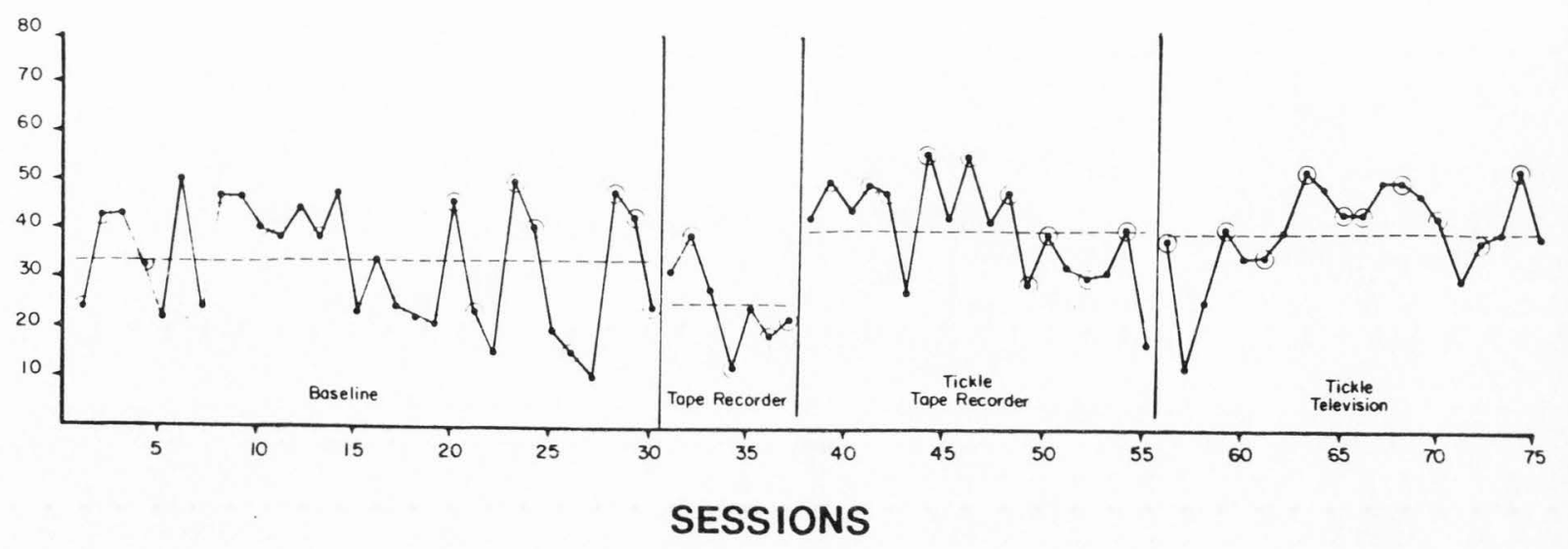


Table 2

Mean EEG Data for Each Subject Per Experimental Condition Mean percent time 8-12 Hz, mean percent time 4-8 $\mathrm{Hz}$, mean frequency of 8-12 Hz activity, and mean amplitude of 8-12 Hz activity for each subject per experimental condition

Sessions \% time \% time Frequency Amplitude 8- $12 \mathrm{~Hz} \quad 4-8 \mathrm{~Hz} \quad \mathrm{~Hz}$

uv

Subject 1 :

$\begin{array}{lrlllll}\text { Baseline } & 1-10 & M & 34.27 & 51.06 & 10.17 & 46.62 \\ \text { Training } & 11-24 & M & 27.27 & 58.63 & 10.19 & 67.82 \\ & 25-27 & M & 27.23 & 57.55 & 10.29 & 55.17 \\ & 28-34 & M & 24.78 & 60.11 & 10.18 & 59.37 \\ & 35-37 & M & 26.03 & 62.69 & 10.12 & 60.08 \\ 38-54 & M & 28.16 & 52.69 & 10.19 & 57.14 \\ 55-74 & M & 30.99 & 50.49 & 10.39 & 59.81\end{array}$

Subject 2:

$\begin{array}{lrrrrrr}\text { Baseline } & 1-20 & \text { M } & 36.82 & 48.88 & 10.26 & 34.30 \\ \text { Training } & 21-65 & \text { M } & 63.25 & 18.68 & 10.68 & 20.75\end{array}$

Subject 3:

$\begin{array}{lrlllll}\text { Baseline } & 1-30 & \text { M } & 33.72 & 47.41 & 10.53 & 49.13 \\ \text { Training } & 31-37 & \text { M } & 25.05 & 64.48 & 10.11 & 75.31 \\ & 38-55 & \text { M } & 40.33 & 41.71 & 10.55 & 60.01 \\ & 56-75 & M & 39.99 & 44.45 & 10.68 & 51.64\end{array}$


showed a decrease and when the feedback included tickles or television he showed an increase in the percent time in 8-12 $\mathrm{Hz}$ activity.

\section{Seizure Data}

The seizure frequency for each subject during baseline, EEG feedback training, and posttraining of these data is provided in Table 3 . These data indicate that $S-7$ 's percent of seizure free days increased from 51 percent during baseline to 71 percent during training, an increase of 20 percent in seizure free days. When EEG feedback was no longer available (posttraining condition) S-l's percent of seizure free days decreased to approximately the same level (47 percent) that occurred during the baseline condition. S-2's percent of seizure free days was essentially the same (24 percent) during the baseline and EEG feedback training conditions. A slight increase (7 percent) of seizure free days occurred during the posttraining condition. S-3's percent of seizure free days increased from 41 percent during the baseline condition to 59 percent during the EEG feedback training condition and then decreased to 37 percent during the posttraining condition.

Figure 4 and Table 3 show that $S-1$ 's mean number of seizures per day increased from .73 per day during baseline to . 31 per day during EEG feedback training and increased to .91 per day during the posttraining condition. S-2's mean number of seizures per day decreased from 2.0 per day during baseline to 1.2 per day during EEG feedback and decreased further to 1.0 per day during the posttraining condition. S-3's mean number of seizure per day decreased slightly from .81 per day during baseline to .75 per day during EEG feedback training. S-3's highest frequency of seizures per day (1.31 per day) occurred during the posttreatment condition. 
Table 3

Percent of Seizure Free days, Actual Number of Seizure Free Days, Mean Number of Seizures Per Day, and Actual Number of Seizures Per Day for Each Subject During Baseline Feedback Training $(T)$, and Posttraining Conditions $(P)$

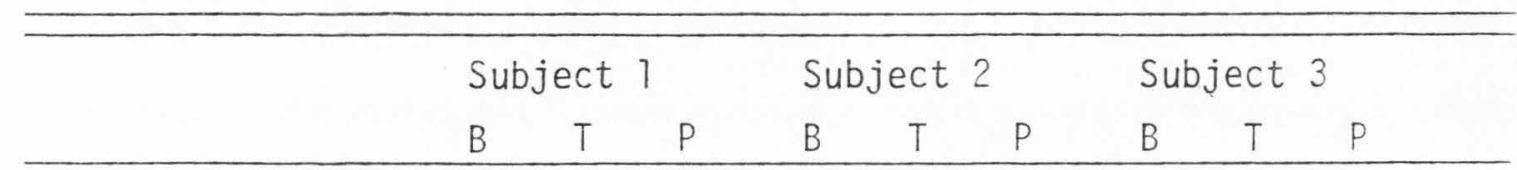

$\begin{array}{llllllllll}\text { Percent of seizure } & 51 & 71 & 47 & 24 & 24 & 31 & 41 & 59 & 37\end{array}$ free days

$\begin{array}{llllllllll}\begin{array}{l}\text { Actual number of } \\ \text { seizure free days }\end{array} & 23 & 32 & 21 & 7 & 7 & 9 & 13 & 19 & 12\end{array}$

Mean number of seizures per day

Actual number of seizures $\begin{array}{lll}.73 & .31 \quad .91\end{array}$

$2.0 \quad 1.2 \quad 1.0$

$\begin{array}{lll}.81 & .75 & 1.31\end{array}$

$33 \quad 14 \quad 41$

5836

29

$26 \quad 24$

42

Note: Combined Baseline (B), EEG Feedback Training ( $T$ ), and Post Training conditions $(P)$, were of same duration of days for each subject: $B, T$, and $P-45$ days for $S-1, B$, $T$, and $P=$ 29 days for $S-2$; and $B, T$, and $P=32$ days for $S-3$ 
Figure 4. Seizure frequency of experimental subjects during baseline training, and posttraining conditions. Each letter indicates the type of feedback provided during specific sessions as follows:
(A) feedback was provided by M\&M dispenser
(B) feedback was provided by hand delivery
(C) feedback was provided by the tape recorder
(D) feedback was provided by light panel
(E) feedback was provided by light panel and television
(F) feedback was provided by tape recorder and tickle
(i) feedback was provided by light panel and television
(H) feedback was provided by television and tickle 
SUBJECT ।

BASELINE

EEG

TRAINING

POST-TRAINING

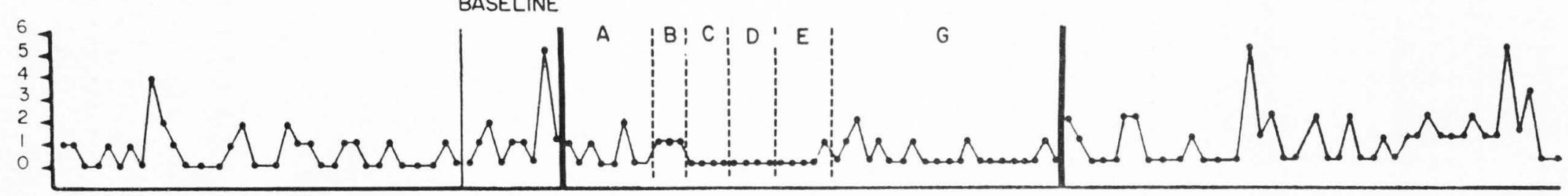

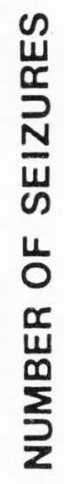

SUBJECT 2

BASELINE

EEG BASELINE

TRAINING

POST- TRAINING

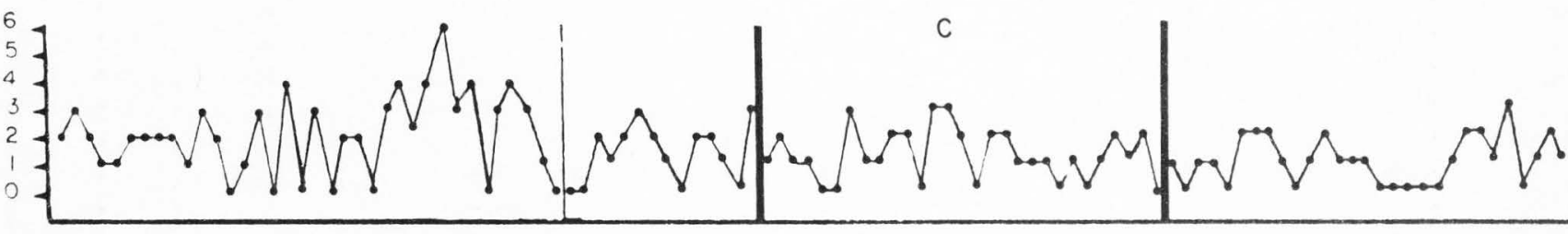

SUBJECT 3

BASELINE

EEG BASELINE

TRAINING

POST-TRAINING

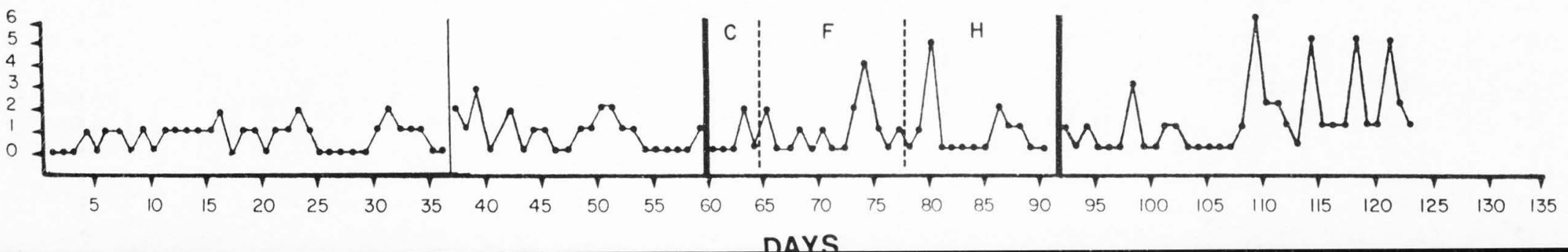


In summary, the results of the study indicate that S-T's mean number of seizures per day during EEG feedback training was lower than the baseline or posttraining conditions. Associated with this decrease in seizures was an increase in the percent of seizure free days during training as compared to either the baseline or posttraining conditions. S-2's mean number of seizures per day decreased during training as compared to baseline. However, this decrease was not associated with an increase in the percent of seizure free days during training as compared with the baseline condition. S-3's percent of seizure free days increased during training and returned to baseline levels during posttraining. For $S-3$ the mean number of seizures per day for both the EEG feedback and baseline conditions were approximately equal, and lower than the posttraining condition.

\section{Reliability}

EEG data. Reliability of EEG data was established by having an independent observer provide reliability checks on the data recorded by the experimenter. The second observer sat in the chamber with the experimenter and independently recorded EEG data displayed by the feedback encephalograph's meters. For each subject, one reliability check was provided during the baseline and two were made during the training period. Product moment correlation coefficients were computed for each measure and served as an index or reliability. The coefficients obtained for each measure were: percent time within 8-12 Hz $=.95$, percent time within $4-8 \mathrm{~Hz}=.97$, mean amplitude of 8-12 $\mathrm{Hz}$ activity $=.97$, and mean frequency of $8-12.4 z$ activity $=.92$. 
Seizure data. A time sampling procedure was used to determine the reliability of seizure reporting by the staff at PSHTC. The experimenter observed each subject for a randomly chosen 30 minute period between the hours of 10:00 a.m. to $12: 00$ noon and 1:00 p.m. to 3:00 p.m., five days per week for a three week period. A total of 45 observations, 15 for each subject were made. During these observation periods the percent agreement between the observer and PSHTC staff was 100 percent, however, no seizures were observed during any of the observation periods. Thus the 100 percent reliability figure represents perfect agreement on the nonoccurrence of seizures.

\section{Related Data}

EEG. Each subject's percent of time within 4-8 Hz, average frequency of 8-12 Hz activity, and average amplitude of 8-12 $\mathrm{Hz}$ activity during EEG baseline and EEG feedback training conditions are shown in Appendix D, E, and $F$ respectively. A summary of these data are provided in Table 2.

Associated with S-1's decrease in 8-12 Hz activity during the EEG feedback training condition was an increase in the mean percent of time of 4-8 Hz activity. This increase was from a mean of 51.06 percent during 10 EEG baseline sessions to a mean of 57.1 percent during 65 EEG training sessions (see Appendix D and Table 2). The mean frequency of 8-12 Hz activity for the 65 training sessions increased to 10.23 as compared to the mean of 10.17 for the 10 EEG baseline session (see Appendix E and Table 2). During sessions 11 through 24, an increase of $20 \mathrm{mv}$ in the mean amplitude of $8-12 \mathrm{~Hz}$ 
activity, as compared to baseline, occurred when $M$ \& $M$ candies were delivered by the $M \& M$ dispenser (see Appendix $F$ and Table 2). However, S-1's mean amplitude decreased to a level approximately $10 \mathrm{mv}$ above baseline level and remained at this approximate value throughout the remainder of the training condition when $M$ \& M's were delivered by the experimenter (sessions 25-27).

Table 2 and Appendix D show that $S-2^{\prime} S$ mean percent of time of 4-8 $\mathrm{Hz}$ activity decreased from 48.88 percent during baseline to 18.68 during the EEG feedback training condition. In addition, an increase in the mean frequency of $8-12 \mathrm{~Hz}$ from $10.26 \mathrm{~Hz}$ during baseline to $10.68 \mathrm{~Hz}$ during training occurred as well as a reduction in the mean amplitude of $8-12 \mathrm{~Hz}$ activity from 34.30 uv during baseline to 20.75 uv during training (see Table 2 and Appendix E and F).

S-3's percent of time of 4-8 Hz activity during sessions (31-37) increased to 64.48 percent from 47.41 percent during the baseline sessions (1-30) see appendix D and Table 2. During these sessions, S-3's mean frequency of 8-12 Hz activity decreased and mean amplitude of 8-12 Hz activity increased as compared to baseline values, see Table 2 and Appendixes $E$ and $F$. During sessions 38-55, the mean percent of time within 4-8 Hz decreases from 64.48 percent during sessions $31-38$ to 41.71 percent which was 5.7 percent below the mean percent of time within 4-8 Hz during the 30 baseline sessions (see Appendix $D$ and Table 2). The mean frequency of 8-12 $\mathrm{Hz}$ activity during sessions $31-37$ decreased to $10.11 \mathrm{~Hz}$ as compared with a mean of 10.53 during baseline sessions 1 through 30 . S-3's mean frequency increased to 10.55 and 10.68 during sessions $38-55$ and $56-75$ respectively when 
feedback was provided by the tape recorder and television (see Table 2 and Appendix E). S-3's mean amplitude of 8-12 $\mathrm{Hz}$ activity during sessions 31-37 increased to 75.37 uv as compared with a mean of 49.13 uv during baseline sessions 1 through 30 . The mean amplitude decreased to 60.01 uv and 51.64 uv during sessions 38-53 and sessions 56-75 respective $7 y$.

AM PM effects. Throughout the study a daily cyclic pattern was observed in various parameters of the subjects' EEG's (see Figure 3 and Appendixes D, E). Appendix G presents the AM PM values for the four EEG parameters measured and indicates which differences were found to be statistically significant using a $T$ test for repeated measurements (Ferguson, 1971). In general S-1 and S-3 exhibited the following daily patterns:

1. Percent time 8-12 Hz activity was highest in the morning.

2. Percent time $4-8 \mathrm{~Hz}$ activity was highest in the afternoon.

3. Mean amplitude of $8-12 \mathrm{~Hz}$ activity was highest in the afternoon.

4. Mean frequency of $8-12 \mathrm{~Hz}$ activity was highest in the morning.

In contrast, S-2 exhibited the exact opposite daily pattern as follows:

1. Percent time 8-12 Hz activity was highest in the afternoon.

2. Percent time $4-8 \mathrm{~Hz}$ activity was highest in the morning.

3. Mean amplitude of $8-12 \mathrm{~Hz}$ activity was highest in the morning.

4. Mean frequency of $8-12 \mathrm{~Hz}$ activity was highest in the afternoon. 


\section{DISCUSSION}

A11 subjects received feedback for the production of 8-12 $\mathrm{Hz}$ activity, however, on 1 y S-2 and S-3 increased their production of 8-12 Hz activity as a result of the training procedures. The most probable explanation for these results was the differing degree of effectiveness of the feedback stimuli used in terms of their functionality as reinforcers. While all subjects received music feedback only $\mathrm{S}-2$ increased her production of $8-12 \mathrm{~Hz}$ activity above baseline levels. S-3 initially showed a decrease in $8-12 \mathrm{~Hz}$ production when provided with music feedback, however, when the feedback included tickles or television he showed an increase in the percent of time in 8-12 $\mathrm{Hz}$ activity. S-7's production of $8-12 \mathrm{~Hz}$ activity remained below baseline levels even though a variety of feedback stimuli were provided. These data suggest that the differential results found between subjects is that the various feedback stimuli had different reinforcing values for the subjects. Possibly contributing to $S-T^{\prime}$ 's inability to master the task was that $S-1$ was the only subject who had been diagnosed by PSHTC staff with psychiatric problems which were characterized by depression and apathy.

Several medication differences between S-2 and S-1 also may have contributed to the difference in results of the training procedure. While all three subjects received in excess of $1000 \mathrm{mg}$. of medication daily, S-1 was the only subject who received Diamox and Librium. Reportedly, diamox does not effect changes in the EEG, however, Librium causes diffuse fast activity, located predominantly in the anterior regions of the cortex, which can persist in the EEG up to two weeks 
after withdrawal of the medication (Craib and Perry, 1975). Possibly Librium's effects may have contributed to $S-T^{\prime}$ 's inability to increase 8-12 $\mathrm{Hz}$ activity. In addition the degree of change, from baseline to training, in $8-12 \mathrm{~Hz}$ activity between $\mathrm{S}-2$ (26.5 percent) and $\mathrm{S}-3$ (6.7 percent) was large. S-2 was the only subject who did not receive Tegretol. Tegretol is a relatively new seizure control medication whose effects on cortical EEG activity are not know. Again medication differences may have accounted for the differences which occurred as a result of training. Future studies regarding the effect of different seizure medications on cortical EEG activity and one's ability to control cortical activity, while receiving these medications should be conducted. Such studies might determine if certain medications facilitate biofeedback training as therapy in the treatment of epilepsy.

Seizures were not totally eliminated in any of the subjects who served in the study, however, the results indicate that all subjects exhibited decreases in some aspect of their seizure activity (the mean number of seizures per day and/or increases in the percent of seizure free days) during the training condition. S-2 and S-3 increased their percent of time of 8-12 $\mathrm{Hz}$ activity during the EEG feedback training condition. Several possible explanations may account for S-7's reduction of seizure frequency not being associated with an increase in 8-12 Hz activity. One explanation is that a change in another physiological parameter may have occurred as a result of the training procedure which in turn effected a decrease in seizures, Kuhlman (1976) successfully reduced seizures by providing feedback for 9-14 Hz central rolandic activity. While no increase in 9-14 Hz activity occurred, 8-12 Hz occipital alpha activity increased, apparently as an indirect 
consequence of the training procedures. Other studies supportive of this hypothesis include Germana (1968) and Schwartz (1976). Germana (1968) reported that when subjects were required to learn a variety of cognitive and motor tasks, initiallearning was accompanied by increases in multiple physiological responses such as heart rate, sweat gland activity, muscle tension, etc. Schwartz (1976) reported that changes occurred in skin conductance when subjects were provided feedback for increasing both $8-12 \mathrm{~Hz}$ activity and heart rate.

In accordance with Germana (1968) and Schwartz's (1976) data another possible explanation for the decrease in seizure frequencies for S-1 becomes apparent. It is possible that as a result of training, S-1 achieved a generally lower level of arousal (e.g., generally lower heart rate and/or muscle tension, etc.) which in turn was responsible for the decrease in seizure rate. As mentioned previously, Kaplan (1975) reported that two subjects who were trained in central rolandic activity experienced reductions in seizure rate that were not associated with an increase in the activity being trained. The subjects, however, indicated that the biofeedback situation provided them with relaxation techniques.

The results of this study and the other biofeedback studies (Sterman, et a1., 1972; Finley, et a1., 1975; Kaplan, 1975; Lubar and Bahler, 1976; Kuhlman, 1976) which have demonstrated decreases in seizure activity after training other physiological parameters suggest that some inadvertently trained common factor, perhaps centrally 10cated, may be responsible for the reductions in seizure frequency. This reflects the need for monitoring multiple physiological parameters 
in future studies of seizure control in an attempt to identify this common factor if it exists.

Al1 of the biofeedback studies regarding the effects of EEG feedback on seizure frequency cited in this dissertation (Finley, 1972; Kaplan, 1975; Kuhlman, 1976; Sterman and Friar, 1972; Sterman, MacDonald, and Stone, 1974) have relied on the use of self report measures of seizure frequency. This study attempted to obtain a measure that was not subject to demand characteristics by using trained observers wio were naive to the purpose of the study, and to provide reliability checks on their recordings. However, due to the low frequency of seizures, the reliability obtained reflected only the nonoccurrence of seizures. This suggest that a time sample method of recording seizures may not be a completely satisfactory method for determining the reliability of seizure activity, particularly when seizure frequencies are low.

Due to the fact that reliability was obtained only on the nonoccurrence of seizures, a post hoc attempt was made to collect additional information. At the end of the study, the seizure activity of three other patients at PSHTC during the time comparable to the experimental periods of the present study were collected by examining the patients medical records. These data were collected in order to compare the seizure frequency of these patients to those who participated in the study, and thus they served as a form of post hoc control group. A comparison of these data (see Appendix G) with those for the experimental subjects (see Table 2) revealed that the change in seizure activity of the control subjects across conditions was not 
as large as the change in experimental subject for two of three subjects (the exception being control subject 2 whose total number of seizures decreased from 16 during baseline to six during training). In examining these data it is difficult to decide what impact the actual number of seizures a subject experienced had on the other seizure data; the control subjects experienced less than one third the total number of seizures exhibited by the experimental subjects. The larger and generaliy more consistent (with the exception of control subject 2) changes in seizure data for the experimental subjects also tends to support the hypothesis that something within the experimental condition resulted in changes in seizure activity parameters. These data also raise some concerns about possible validity of the seizure data collected; thus a more accurate seizure monitoring system should be developed. Some possible alternatives would be the use of 24 hour monitoring via a videocamera and EEG such as is available at the comprehensive seizure control unit at the Utah State Training School in American Fork, Utah; or the use of a portable EEG which permits twenty-four hour monitoring of the EEG. A portable device has been developed by Dr. Fergusen at Case Western Reserve University and it's use would permit more reliable monitoring of seizure activity.

Menkes (1974) and Schmidt and Wilder (1968) point out that mental and emotional deterioration may occur in patients who seizures are uncontrolled. The training procedure reported in this study decreased some paramater of seizure activity in all of the subjects. It is not known, however, if this reduction had an ameliorative effect on this 
possible deterioration. Longitudinal studies comparing subjects who received treatment to subjects not receiving treatment are needed to assess the clinical impact of this type of therapy. This could be done by using a group design or a single subject multiple baseline design. The latter appears more feasible considering the difficulty in obtaining appropriate subjects. Anecdotally, two of the three subjects wore protective headgear to lessen the impact of a fall when they experienced seizures. Since the frequency of seizures decreased as a result of training, the number of fails decreased similarly. Concomitantly, the possible trauma from falls also decreased.

The results of the study suggest change in procedures will be necessary if 8-12 Hz occipital training is to be developed into an adjunctive therapy in the treatment of epilepsy. However, essential components of these studies should include subjects with a higher frequency of seizures, subjects of normal intelligence, and the simultaneous recording of several other physiological parameters such as heart rate, muscle activity, galvanic skin potentials, etc. These methodological improvements would provide a more accurate assessment of the effectiveness of all EEG biofeedback techniques used in the treatment of epilepsy. 
LITERATURE CITED

Adams, K. M. Behavioral treatment of reflex or sensory-evoked seisures. Journal of Behavior Therapy and Experimental Psychiatry, 1976, 7 , 123-127.

Arangio, A. J. Behind the stigma of epilepsy. Epilepsy Foundation of America, Washington, D.C., 1974.

Arieff, A. J. Treatment needs of the epileptic: the adult. Modern Dimensions of Epilepsy. Proceedings of an Inter-Regional Training Conference, Chicago, I11inois, 1974, 29-35.

Balaschak, B. A. Teacher-implemented behavior modification in a case of organically based epilepsy. Journal of Consulting and Clinical Psychology, 1976, 44, 218-223.

Baer, D. M., Wolf, M. M., and Risley, T. R. Some current dimensions of applied behavior analysis. Journal of Applied Behavior Analysis, $1968,1,91-97$.

Beatly, J. Similar effects of feedback signals and instructional information on EEG activity. Physiology and Behavior, 1972, 9, $151-154$.

Black, A. H. The operant conditioning of central nervious system electrical activity. In G. H. Bower (Ed.), The Psychology of Learning and Motivation. Vol 6. N.Y: Academic Press, 1972.

Boshes, L. D. Medical treatment of seizures in children. Disease of the Nervous System, 1971, 32, 686-689.

Boshes, L. Epilepsy: historical review in modern dimensions of epilepsy, Proceedings of an Inter-Regional Training Conference, $1974,6-15$.

Cabral, R. J. \& Scott, D. F. Effects of two desensitization techniques biofeedback and relaxation, on intractable epilepsy: follow-up study. Journal of neurology, neurosurgery and psychiatry, 1976, 39, 504-507.

Craib, A. R., and Perry, M. EEG Handbook, Schiller Park, I11 inois: Beckman Instruments, 1975.

Creutzfeldt, 0. D. Synaptic organization of the cerebral cortex and its role in epilepsy. In Brazier, M.A.B. (Ed.), Epilepsy its phenomena in man, N.Y.; Academic Press, 1973, 11-27. 
Efron, R. The effect of olfactory stimuli in arresting uncinate fits. Brain, 1956, 79, 267-277.

Efron, R. Conditioned inhibition of uncinate fits. Brain, 1957, 80 , $251-262$.

Ferguson, G. A. Statistical Analysis Psychology and Education, New York: McGraw Hi11, 1971.

Finley, W. W. Effects of sham feedback following successful SMR training in an epileptic: Follow-up study. Biofeedback and SelfRegulation, in press.

Finley, W. W., Smith, H. A., Etherton, M. D. Reduction of seizures and normalization of the EEG in a severe epileptic following sensorimotor biofeedback training. Preliminary Study. Biological Psychology, 1975, 2, 189-203.

Forster, $F$. Conditioning of cerebral dysthythmia induced by pattern presentation and eye closure, Conditional Reflex, 1967, 2, 236.

Forster, F. Conditional reflexes and sensory evoked epilepsy: The nature of the therapeutic process, Conditional Reflex, 1969, $\underline{4}$, 103- 114 .

Forster, F. M. The classification and conditioning treatment of the reflex epilepsies. International Journal of Neurology, 1972, $\underline{9}$, 73-86.

Forster, F. M., Hansotia, P., Cleeland, C. S. \& Ludwig, A. A case of voice-induced epilepsy treated by conditioning. Neurology, 1969, 19, 325-331.

Forster, F. M., Paulsen, W. A. \& Baughman, F. A. Clinical therapeutic conditioning in reading epilepsy. Neurology, 1969, 19, 717-723.

Gardner, J. Behavior therapy treatment approach to a psychogenic seizure case. Journal of consulting psychology, 1967, 31, 209-212.

Germana, J. The psychophysiological correlates of conditioned response formation. Psychological Bulletin, 1968, 70, 105-14.

Gloor, P. Neurophysiological bases of generalized seizures termed centrencephal is. In H. Gastant et al. (Eds), The Physiopathogenesis of the Epilepsies, Springfield, Illinois: Thomas, 1969.

Grossman, H. Manual on terminology and classification in mental retardation. American Association on Mental Deficiency/Special Publication No. 2, Baltimore: Garamond/Pridemark Press, 1973.

Heber, R. Measures intelligence: A manual on terminology and classification in mental retardation. American Journal of Mental Deficiency, (Monograph Supplement), $1961,6 \overline{4}, 57-60$. 
Ince, L. P. The use of relaxation training and a conditioned stimulus in the elimination of epileptic seizures in a child: A case study. Journal of behavior therapy and experimental psychiatry, 1976, 7 , $39-42$.

Jacobson, E. Progressive relaxation, Chicago: University of Chicago Press, 1938.

Kamiya, J. Operant control of the EEG alpha rhythm and some of its reported effects on consciousness. In C. T. Tart (Eds.), Altered states of consciousness. N.Y.: John Wiley and Sons, 1969, pp. 480-501

Kaplan B. EEG biofeedback and epilepsy. In proceedings of biofeedback research society: Annual meeting. Colorado Springs, Colorado, 1974.

Kaplan, B. J. Biofeedback in epileptics: equivocal relationship of reinforced EEG frequency to seizure reduction. Epilepsia, 1975, $16,477-485$.

Kuhlman, W. W. EEG feedback training in epileptic patients: clinical and neurophysiological analysis. Presented at the 7 th Annual Meeting of the Biofeedback Research Society, 1976.

Lennox, W. G. Epilepsy and related disorders, Boston: Little, Brown, 1960.

Liftshitz, F., Maclaren, N. K. Vitamin-D dependent rickets in institutionalized mentally retarded children receiving long term anticonvulsant therapy. Journal of Pediatrics, 1973, 83, 612-620.

Lubar, J. L. and Bahler, W. W. Behavioral management of epileptic seizures following EEG biofeedback training of the sensormotor rhythm. Biofeedback and Self Refulation, 1976, I, 77-104.

Menkes, J. H. Textbook of child neurology. Philadelphia: Lea and Febiger, $197 \overline{5}$

Parrino, J. J. Reduction of seizures by desensitization. Journal of behavior therapy and experimental psychiatry, 1971, 2, $215-218$.

Penfield, W. and Ericksen, T. C. Epilepsy and cerebral localization. Springfield, Illinois: C. C. Thomas, 1941.

Poirel, C. Les rythmes arcadiens de l'epilepsie en psychopathologie comparee, Annales Medico-Psychologiques, 1971, 2, 699-710.

Roth, S. R, Storman, M. B., and Clemente, C. D. Comparison of EEG correlates following sensorimotor EEG feedback training. Electroencephalography and Clinical Neurophysiology, 1972, 33, 89-95. 
Schmidt, R. P. and Wilder, B. J, Epilepsy. Philadelphia: F. A. Davis Co., 1968.

Schwartz, G. E. Biofeedback, self-regulation, and the patterning of psychiological processes. American Scientist, 1975, 63, 314-324.

Sterman, M. B., and Friar, L. Suppression of seizures in an epileptic following sensorimotor EEG feedback training. Electroencephalography and Clinical Neurophysiology, 1972, 33, 89-95.

Sterman, M. B., LoPrest, R. W., and Fairchild, M. D. Electroencephalographic and behavioral studies of monomethyl hydrazine toxicity in the cat. Technica] Report AMRL-TR-69-3, Air Systems Command, Wright-Patterson Air Force Base, Ohio, 1969.

Sterman, M. B., Macd nald, L. R., and Stone, R. K. Biofeedback training of the sensorimotor electroencephalogram rhythm in man: effects on epilepsy. Epilepsia, 1974, 15, 395-416.

Sterman, M. D. and Wyrwicka, W. EEG correlates of sleep: evidence for separate borebrain substrates. Brain Research, 1962, 6, 143-163.

Zlutnick, S., Mayville, W. J. \& Moffat, S. Modification of seizure disorders: the interruption of behavioral chains, Journal of Applied Behavior Analysis, 1975, 8, 1-12. 
APPENDIXES 
APPENDIX A

Difficulty in Subject Identification 
APPENDIX A

Major efforts were involved in attempts to identify subjects for this dissertation who resided in the state of Utah. The experimenter advertised for subjects in the Utah State University student body newspaper, the local community newspaper; and feature stories describing the research project were published in the local community newspaper as well as the two major Salt Lake City, Utah, newspapers. In addition, the experimenter contacted for referrals: local physicians; 10 neurologists practicing in the Ogden and Salt Lake City areas; and the following institutions: University of Utah Medical Center, Primary Childrens Hospital, Crippled Childrens Hospital and American Fork Training School. No referrals resulted from the above efforts and the experimenter contacted two out-of-state institutions, Wyoming State Hospital in Evanston, Wyoming, and Parsons State Hospital and Training Center (PSHTC) in Parsons, Kansas. Wyoming State Hospital did not have a sufficient population of seizure patients and subject selection was limited to Parsons State Hospital and Training Center. 
APPENDIX B

Parsons State Hospital and Training Center Seizure Reporting Forms 
NAME:

MEDICATIOs: Please chart Dosage and Time

WEIGIT

DATE WEIGIED

to be given. If there is a change in

medication during the month please give date. IF SEIZURES ARF OBSERVED DURIN MONTH PLEASE CORPLETE BACK OF FORM

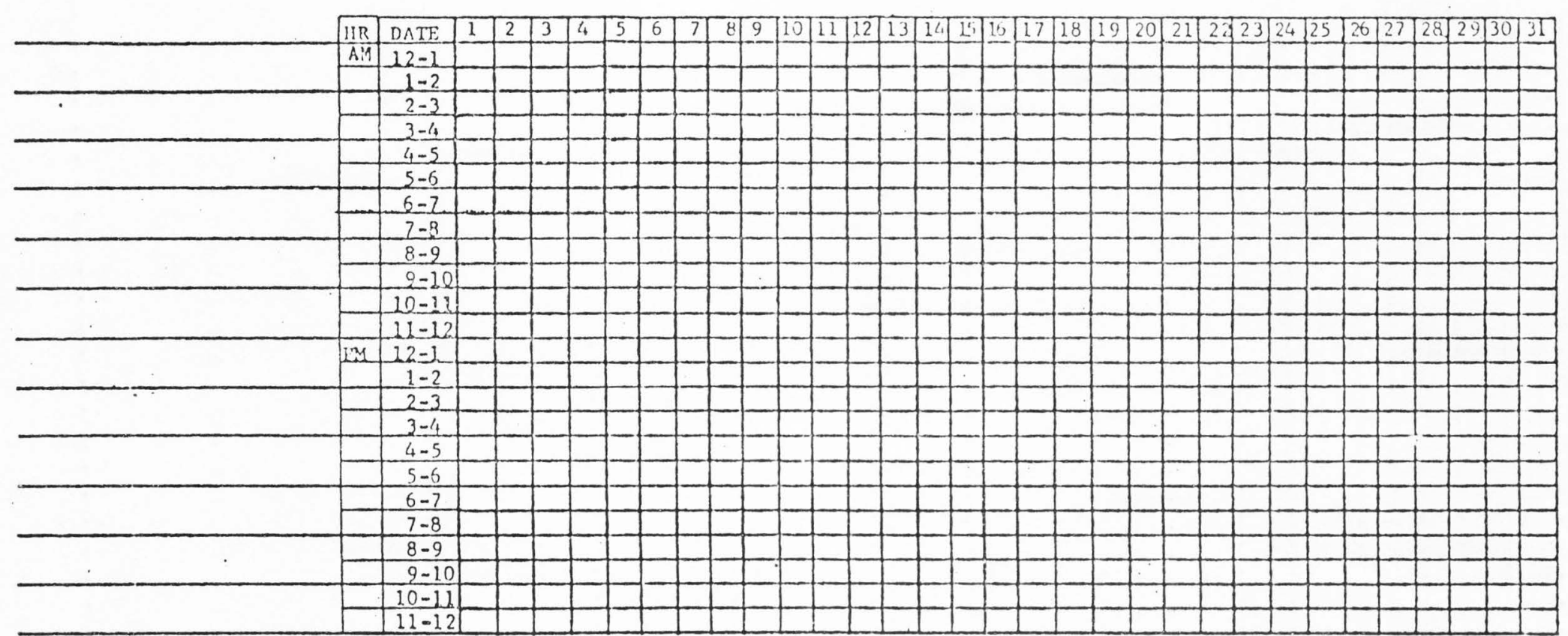

CODE FOR CHARTING SEIZURES:

IF MORE THAN ONE SEIZURE OBSERVED DURING HOUR'S TDME, INSERT NUMBER AND CODE

$\checkmark$ FOR MNOR CONVULSION if there is a sudden $108 \mathrm{~s}$ of consclousness, the body is rigid, and there is associated sycmetrict (Crand Mal) movement of extremities and/or other muscle groups, i.e., face, jaw, neck, shoulders.

L or R FOR. MNJOR FOCAL CONVULSION if there 18 a sudden $10 \mathrm{~s}$ of consciousness, the body is rigid, and there is associated (L for left or $R$ for right) asymetrical movement of extremities, or ruscle groups, as above.

O. FOR MINR CONVISION if there is sudden alteration of alertness (fixed stare, sudden short jerk, suddenly falls, (Pot1t Mal) appears dazed) of short duration with little or no associated movewents, no incontinenci

$x$ OTrER (Psychowotor, etc., describe on back) Ak1net1c, Autonom1c, Mpoclon1c, Psychomotor, M1xed. unclass. 
APPENDIX C

Figure 5. Mean percent of time per session within 4-3 Hz for experimental subjects 1,2 and 3 . The dotted 1 ine represents the mean percent of time for each feedback condition. The circled data points indicate a.m. sessions 


\section{SUBJECTI}

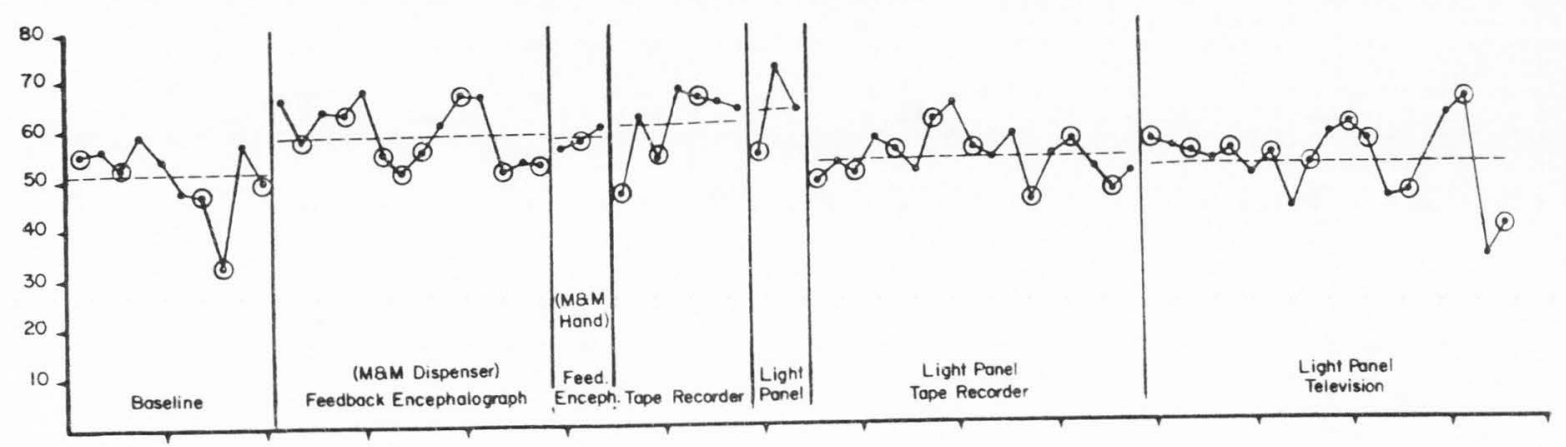

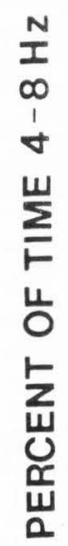

\section{SUBJECT 2}
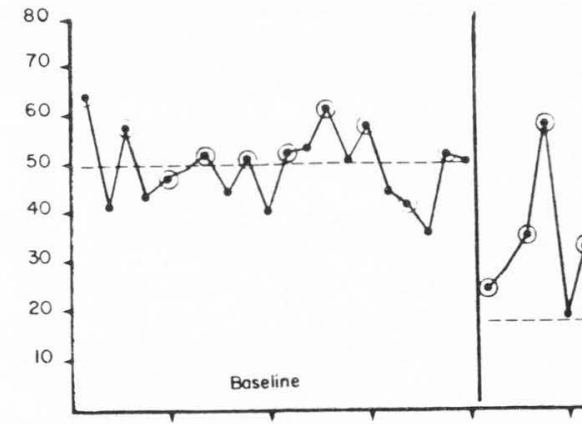

SUBJECT 3

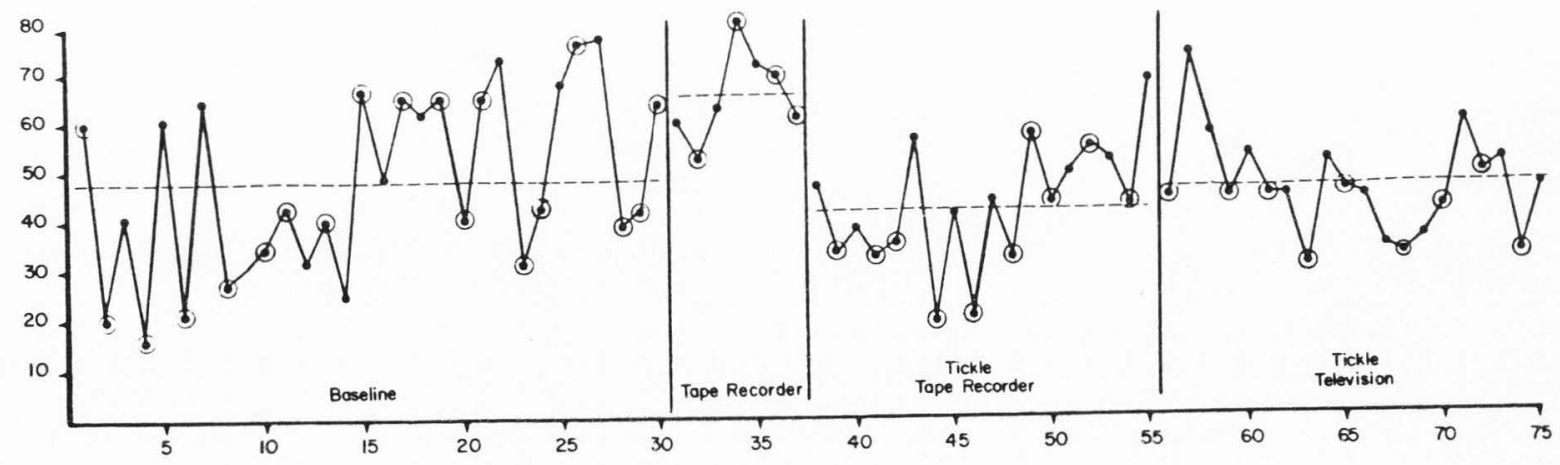

SESSIONS 
APPENDIX D

Figure 6. Mean frequency of 8-12 Hz activity per session for experimental subjects 1,2 and 3 . The dotted line represents the mean frequency for each feedback condition. The circled data points indicate a.m. sessions 


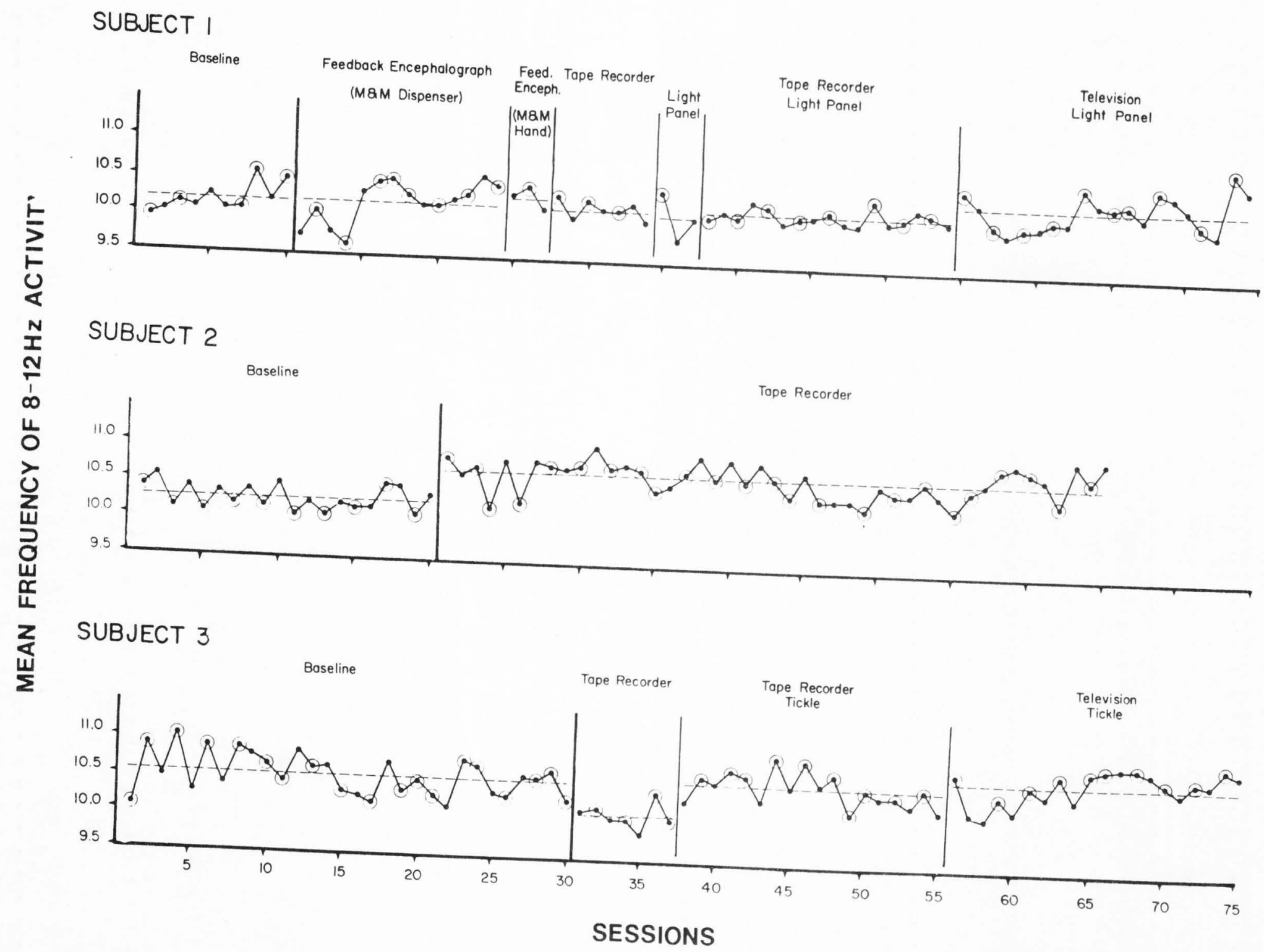


APPENDIX E

Figure 7. Mean amplitude of 8-12 Hz activity per session for experimental subjects 1,2 and 3 . The dotted line represents the mean frequency for each feedback condition. The circled data points indicate a.m. sessions 


\section{SUBJECT I}

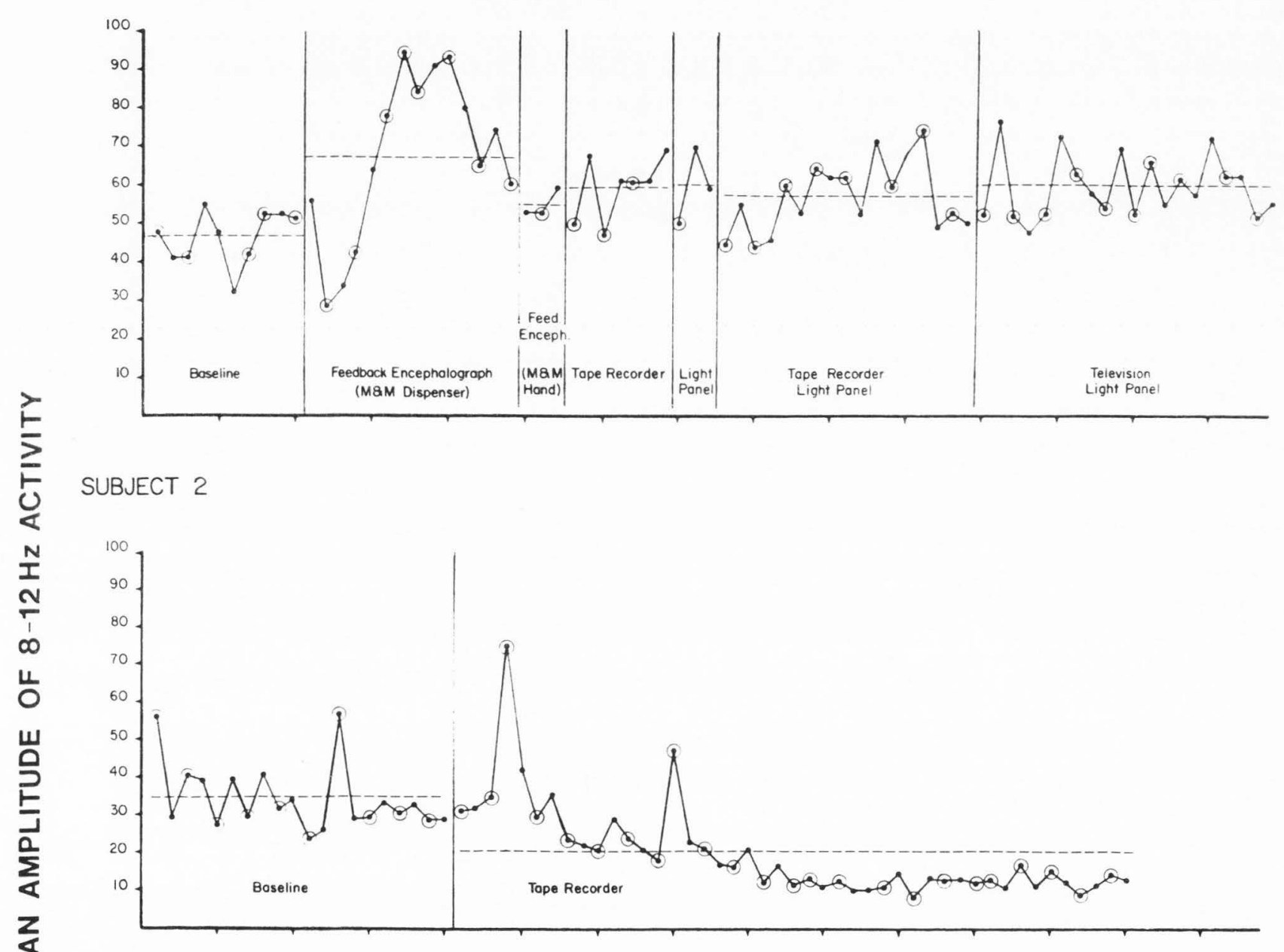

SUBJECT 3

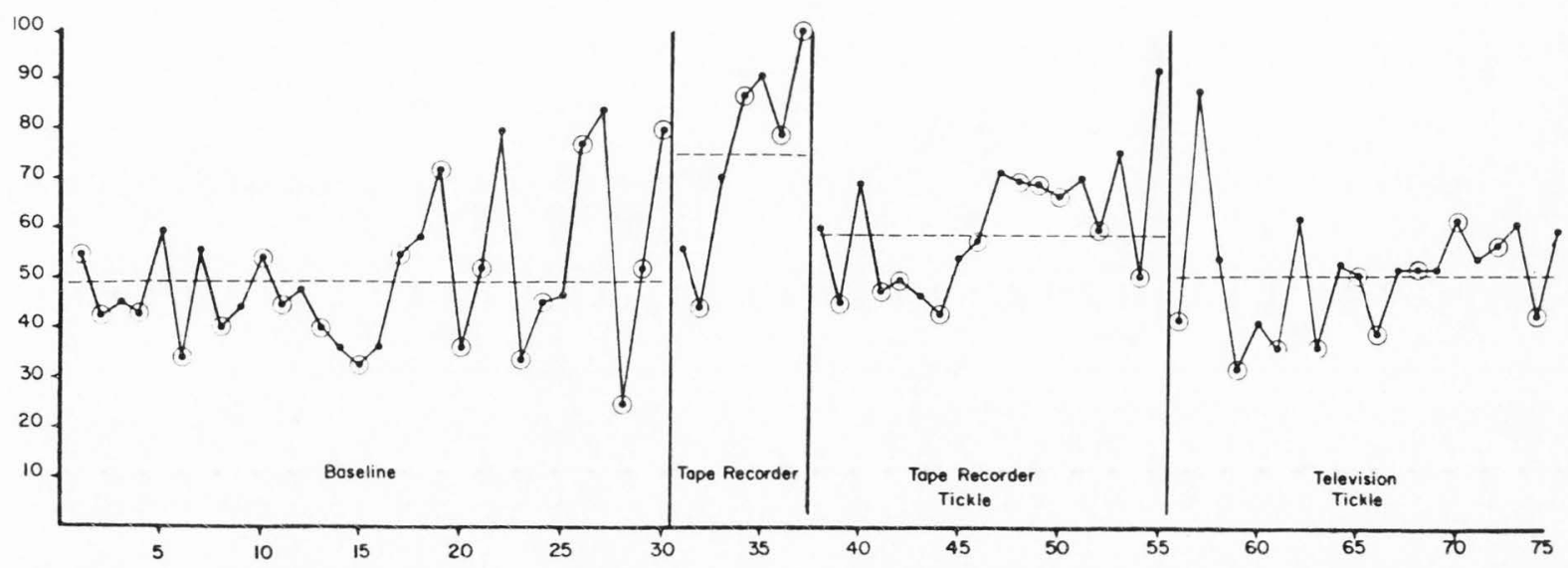




\section{APPENDIX $F$}

\section{Table 4}

am/pm Effect on Daily Means of 8-12 Hz Activity, 4-8 Hz Activity, Mean Amplitude of 8-12 Hz Activity, and Mean Frequency of 8-12 Hz Activity ${ }^{1}$ for experimental subjects 1,2 , and 3

\begin{tabular}{|c|c|c|c|c|c|c|c|c|}
\hline & \multicolumn{2}{|c|}{$8-12 \mathrm{~Hz}$} & \multicolumn{2}{|c|}{$4-8 \mathrm{~Hz}$} & \multicolumn{2}{|c|}{ Mean Amplitude } & \multicolumn{2}{|c|}{ Mean Frequency } \\
\hline & am & $p m_{i}$ & am & $\mathrm{pm}$ & $a m_{i}$ & $\mathrm{pm}$ & $\mathrm{am}$ & $\mathrm{pm}$ \\
\hline Subject 1 & 31.33 & $27.01^{x}$ & 51.79 & $56.92^{X}$ & 57.04 & 60.2 & 10.3 & $10.18^{x x}$ \\
\hline Subject 2 & 52.45 & 57.57 & 30.28 & 25.45 & 25.41 & 23.77 & 10.43 & $10.65^{x x}$ \\
\hline Subject 3 & 38.24 & 35.06 & 42.54 & $50.48^{x x}$ & $\times \quad 49.93$ & $59.42^{x}$ & 10.61 & $10.46^{x x}$ \\
\hline
\end{tabular}

$X=$ significant at $p .05$

$x x=$ significant at $p .10$

T Test for Repeated Measurements (Ferguson, 1971).

1. am/pm data computed represent mean session values for two consecutive sessions that occurred during the same day. Fiftysix sessions met this criterion for $\mathrm{S}-1$; 52 sessions for $\mathrm{S}-2$; and 54 sessions for $\mathrm{S}-3$. 


\section{PLEASE NOTE:}

This page not included in material received from the Graduate School. Filmed as received. UNIVERSITY MICROFILMS 
APPENDIX H

Glossary of Terms 
Absence - generalized seizure which results in a brief laps in consciousness, also referred to as petitmal seizures.

Akinetic - without movement; in reference to seizures, seizures in which there is a sudden arrest of movement.

Atonic - without tone; in reference to seizures, seizures in which there is a sudden loss of muscle tone.

Aura - refers to a pre-seizure sensation i.e. blurring of vision, strange feeling, etc.

Cerebral cortex - the outer layer of gray tissue of the cerebral hemispheres largely responsible for higher nervous system functions.

Cerebrum - large rounded structure of the brain occupying most of the cranial cavity which is divided into two cerebral hemispheres.

Clonic - rhythmic jerking movements.

Contralateral - refers to the opposite side; i.e. contralateral hemisphere refers to the left hemisphere controlling the right side of the body and vicaversa.

Discharge - high voltage sudden changes in the EEG. These are usually described as spike, ploy spike, spike and wave discharges.

Electroencephalogram - record of the electrical impulses of the cortical brain cells.

Focal - refers to a selective localization of brain wave discharges or movement patterns during seizures.

Generalized seizures - refers to a group of seizures which originates and involves both cortical hemispheres.

Hertz $(\mathrm{Hz})$ - cycles per second.

Ictal - refering to a seizure.

Idiopathic seizures - generalized seizures due to no apparent cause (old definition).

Ipsilateral - refers to the same side; i.e. an ipsilateral EEG discharge would refer to a EEG discharge occurring in the left hemisphere with left side symptomatology.

Myoclonus - small groups of muscles going into either a single or repetitive jerking movements. 
Partial seizures - seizures which originate from a particular site of a single hemisphere, i.e. Jacksonian epilepsy originates near the rolandic cortex, see figure 1 .

Poly spike - a repetitive groups of spikes on the EEG.

Postictal - immediately after a seizure.

Psychomotor seizures - seizures originating from the temporal lobe.

Reflex epilespy - refers to seizures which are triggered by particular stimuli or class of stimuli.

Slow wave - in reference to the EEG, wave patterns with frequencies less than 8 hertz.

Spike - in reference to the EEG, a high voltage sharp wave form.

Spike wave discharge - in reference to the EEG, a spike and slow wave complex.

Symptomatic seizures - focal seizures caused by brain trauma (old definition).

Tonic - in reference to a seizure, increased muscle tone during a seizure activity. 
VITA

Eric H. Rudrud 
VITA

Eric H. Rudrud

\section{Personal Data}

Place of Birth: Dayton, Ohio

Date of Birth: August 3, 1950

Marital Status: Married, no dependents

Current Address: Center for the Developmentally Disabled University of South Dakota

Vermillion, South Dakota 57069

Telephone: $\quad$ 605-677-5317

\section{Education}

Ph.D.

Utah State University, Psychology

Dissertation - Eight to Twelve Hertz

Occipital EEG Training with Moderate and

Severely Retarded Epileptic Individuals

M.S.

Utah State University, Counseling Psychology, 1974

Thesis - The Production and Prevention of Stomach Ulcers and Rodents

B.S. Colorado State University, Psychology, 1972

\section{Employment and Experiences}

1977-present

$1975-1977$
Staff Training Specialist, Developmental Disabilities Training Program. Duties include providing technical assistance and on-site training for persons serving the developmentally disabled. Other activities include development of a management training program and resource materials room.

Staff psychologist, Exceptional Child Center Utah State University. This was a one-half time position, duties included serving as intake coordinator and member of mult $i-$ disciplinary teams, conducting intakes, administering educational and psychological 
$1974-1975$

$1974-1975$

1973-1974

$1972-1974$

$1972-1973$ tests, planning and executing behavioral treatment programs, writing psychological reports, parent/child counseling, consulting with school personnel, and supervision of graduate practicum students in interview, assessment, and treatment techniques. One year of this experience was credited as a clinical internship.

Biofeedback Research Assistant at the Exceptional Child Center, Utah State University. Experiences included grant writing, consultation of experimental design paradigms, development of a seizure reporting form, data analysis, subject identification procedures, and the use of EEG, EMG, and skin temperature biofeedback training procedures. Major emphasis was in the area of EEG biofeedback on seizure frequency with both retarded and nonretarded children and adults. Interest and periodic involvement in the lab has continued during the past two years.

Clinical Intern at Utah State Training School, American Fork, Utah. Experiences included psychodiagnostic assessment, behavioral and educational treatment programs for severely handicapped children, teacher/staff consultation, and development of inservice training program in behavior modification.

Research Assistant in Educational Psychology at Utah State University. Experiences included development of criterion referenced individualized instructional packages for student teachers (i.e., task analysis, behavior management, and affective reinforcement).

Research Assistant in Psychological Psychology at Utah State University. This position was comprised of one year paid experience and one year non-paid experience. Duties included grant writing, consultation on experimental design paradigms, data analysis, and physiological experimentation with laboratory animals (dosage/ response curves, simple animal surgery). Major emphasis was investigation of the effects of L-ascorbic acid on various types of stomach ulceration in rodents.

Member, Graduate Student-Faculty Relations Committee of the Psychology Department at Utah State University. 
$1971-1972$

$1970-1972$
Instructor, Physical Education Department, Colorado State University. Course - Advanced First Aid for three quarters.

Member/Director Roadhouse Crisis Center, Colorado State University. Experiences included involvement with a variety of crisis situations (drug overdose, suicide, etc), and provision of outreach services to local community agencies and community liason service (referral and information services).

\section{Practicum Experiences}

Child Psychology Practicum (3 Quarters) - Experiences included observation and recording of behavior, methodological issues in behavioral observation, single subject design, ethics, operational definition of target behaviors, developing and implementing of treatment programs, serving as intake coordinator of multidisciplinary team, assessment, and report writing.

Counseling Psychology Practicum (6 Quarters) - Six hundred hours of supervised counseling practicum. Experiences included individual counseling, group counseling techniques, parent/child counseling, ethics, and psychodiagnostic assessment.

\section{Fields of Present Major Scientific Interests}

Biofeedback; clinical intervention and assessment; child development (normal and deviant); behavior therapy; and analysis of behavior.

Membership - Professional Organizations

Biofeedback Society of America, 1976-present

School Psychologist, Utah State Board, 1975-present

Publications

Cheney, E.D., and Rudrud, E. Prophylaxis by vitamin C in starvation induced rat stomach uleceration. Life Sciences, 14, 1974, 2209-2214.

\section{Papers Presented}

Rudrud, E. and Delworth R. Road house, who do students think we are? Rocky Mountain Physiological Assocation, 1972. 
Rudrud, E. and Cheney, C.D. Ascorbic acid as a protective agent against stomach lesions in rats. Utah Academy of Sciences, Arts and Letters, Ogden, 1973.

Rudrud, E, and Cheney, C.D. Vitamin C protection against starvation stress stomach ulceration in rats. Rocky Mountain Psychological Association, Denver, May, 1974.

Striefel, S. and Rudrud, E. Social and psychological changes in individuals having epilepsy. Utah Seizure Control Clinic, Logan, Utah, May 13, 1975.

Unpublished Manuscripts

Towards a Functional Nomenclature in Epilepsy, in preparation.

\section{Grant Support}

Cheney, C.D. (Principal Investigator) and Rudrud, E. (CoPrincipal Investigator). Vitamin $C$ as a Critical Factor in Rate Gastrointestinal Pathology Prevention and Treatment. Department of Psychology, Utah State University, 1973-1974.

Striefel, S. (Principal Investigator) and Rudrud, E. (CoPrincipal Investiagor). The Effects of SMR Conditioning on Seizure Activity in Retarded Children, Exceptional Child Center, Utah State University, 1974-1975.

\section{References}

Sebastian Striefel, Ph.D.

Director of Division Services

Exceptional Child Center, UMC 68

Utah State University

Logan, UT 84322

(801) 752-4100 extension 8273

Phyllis Cole

Coordinator of Assessment and Treatment

Exceptional Child Center, UMC 68

Utah State University

Logan, UT 84322

(801) 752-4100 extension 8273

Reed Morri11, Ph.D,

Chief Psychologist

Wyoming State Hospital

Evanston, Wyoming 82930 
Glendon Casto, Ph.D.

Assistant Director

Exceptional Child Center, UPic 68

Utah State University

Logan, Utah 84322

(801) 752-4100 extension 8273

Elwin Nielsen, Ph.D.

Psychology Department, UIMC 28

Utah State University

Logan, UT 84322

(801) 752-4100 extension 7254 